\title{
Paisajes culturales extremos en Tierra del Fuego **
}

\author{
Extreme cultural landscapes in Tierra del Fuego
}

$<$ Resumen>

Este artículo analiza la aplicación del concepto de paisaje cultural extremo a la isla de Tierra del Fuego (Chile). Esta perspectiva de análisis es complementada con la noción de palimpsesto, al modo de capas superpuestas como forma de lectura de la ocupación del territorio.

$<$ Abstract $>$

This article analyzes the application of the concept of extreme cultural landscape to Tierra del Fuego /sland (Chile). This perspective of analysis

is complemented with the notion of palimpsest (overlapping layers) as a way of understanding the occupation of the territory in the past.

$<$ PALABRAS CLAVE>

PAISAJE CULTURAL EXTREMO / TIERRA DEL FUEGO / OCUPACIÓN DEL TERRITORIO / PALIMPSESTO

-KEYWORDS >

EXTREME CULTURAL LANDSCAPE / TIERRA DEL FUEGO / OCCUPAT ION OF THE TERRITORY / PALIMPSEST

\section{Introducción}

Nicanor Parra lo ha señalado acertadamente: Chile es un paisaje más que un país. Sin embargo, el antipoeta juega con las palabras, ya que en la etimología de paisaje están país y paisano. En este sentido, la identidad de un país estaría relacionada con sus paisajes y su gente, quienes han construido esa identidad en base a la frecuentación y disfrute de sus bellezas naturales, así como al cultivo y utilización asidua de los recursos que ofrece el territorio. Jocelyn-Holt por su parte, y en referencia a las montañas, el agua y el valle de Santiago, afirma que sus paisajes serían «parte de la historia y no sólo de la naturaleza» ${ }^{1}$. Benjamín Subercaseaux, con su Chile o una loca geografía, abre paso a la formulación de una identidad que surge desde una geografía metafísica², en la que convergen historia y paisaje, según la cual el territorio está fragmentado en distintos países - «de las mañanas tranquilas», «de la senda interrumpida», «de la montaña nevada», «de la tierra inquieta», «de los espejos azules», «de la noche crepuscular»-y que sin embargo es uno, en la medida que «quedará en definitiva ocupado por chilenos; por hombre sujetos a la misma historia y a un mismo paisaje que les modelará un mismo carácter, los exaltará en las misma glorias y los hará sobrellevar las mismas miserias» ${ }^{3}$. Mariano Latorre dijo en cierta ocasión: «Era necesario ser paisajista, pues el gran personaje es aquí la naturaleza» ${ }^{4}$. Leopoldo Castedo, en su Redacción, iconografía y notas al Resumen de la Historia

* Profesor titular de la Facultad de Arquitectura, Diseño y Estudios Urbanos (FADEU) de la Pontificia Universidad Católica de Chile (PUC), desde 1990. Es arquitecto, Universidad de Chile (1973) y Doctor Arquitecto (UPC), Barcelona, (1987). En 1986 fue Decano de la Facultad de Arquitectura de la Universidad Católica del Norte. Desde 1990 se integró a la Facultad de Arquitectura, Diseño y Estudios Urbanos de la Pontificia Universidad Católica de Chile. Email: egarcesf@uc.cl

** Este paper está basado en la investigación FONDECYT 1030580 «Las formas de ocupación del territorio en Tierra del Fuego». Ver: www.tierradelfuegochile.com

Alfredo Jocelyn-Holt. Historia general de Chile. Tomo 3, 2008; p. 102.

2 Así llama Benjamín Subercaseaux a la cuarta dimensión de la geografía que propone en su Chile o una loca geografía, 2001; pp. 19-20.

3 Ibidem, pp. 20-21.

4 Mencionado por Hernán del Solar en su introducción al libro Chile, país de rincones, de Mariano Latorre, 2000; p. 13. 
de Chile de don Pancho Antonio Encina ${ }^{5}$, señala que la colaboración encontrada en todas partes fue decisiva para «reunir en esta obra un verdadero catálogo de la iconografía chilena» ${ }^{6}$. Debemos convenir que ese catálogo barajado dentro de su Resumen, ha sido una de las contribuciones más importantes a la representación de la identidad chilena, en la forma de grabados, piezas cartográficas, pinturas, fotografías, planos, etc., que se suceden en la obra para construir un espejo en el que nos reconocemos como tales chilenos.

En La Morfología del Paisaje, Carl Sauer ${ }^{7}$ estableció la noción de paisajes culturales como aquellos que surgen a partir de formas antrópicas superpuestas al paisaje natural, destacando el rol que juega el hombre en la modificación de la faz de la tierra, haciendo más compleja la comprensión del paisaje en la forma de fenómenos interdependientes y conectados: «El contenido del paisaje se encuentra por tanto en las cualidades físicas del área que son significantes para el hombre y en las formas de su uso del área, en hechos de sustento físico y hechos de cultura humana... La cultura es el agente, el área natural es el medio, el paisaje cultural es el resultado» ${ }^{8}$

Por su parte, la Convención del Patrimonio Mundial adoptada por la conferencia general de la Unesco (1972), creó un instrumento para reconocer y proteger el patrimonio natural y cultural de valor excepcional y en 1992 incorporó la categoría de paisajes culturales $^{9}$. Unesco distingue los paisajes culturales creado por el hombre (jardines, parques...), muchas veces relacionados con edificios religiosos y monumentos; los paisajes culturales que reflejan por su forma y componentes determinados procesos de evolución, en relación y respuesta a un entorno natural, que han surgidos por motivos sociales, económicos, administrativos o religiosos; y los paisajes culturales que surgen de una potente asociación cultural, religiosa o artística con ciertos elementos naturales no demasiado significativos.

Joaquín Sabaté ha instrumentalizado el concepto a partir de numerosos artículos, actividades académicas y proyectos, consiguiendo proponer una definición muy sintética y operativa, según la cual un paisaje cultural, en términos generales, es «un ámbito geográfico asociado a un evento, a una actividad o a un personaje histórico, que contiene por tanto valores estéticos y culturales» ${ }^{10}$.

Por otra parte, la construcción cultural de paisaje encuentra bases analíticas y operativas en la comprensión de los territorios en términos de capas sobrepuestas de ocupación, cuya lectura resulta complementaria con la figura del palimpsesto, según la cual el territorio se encuentra sobrecargado de huellas, interpretaciones y lecturas, acumuladas, borradas, sobreimpresas en un espacio físico que las condensa y las dota de sentido. La idea del territorio como palimpsesto fue formulada por André Corboz ${ }^{11}$, para quien éste es la consecuencia de diversos procesos que lo construyen de manera incesante y lo constituyen en un producto activado por numerosas acciones que se superponen a modo de estratos en los cuales coexisten los diversos vestigios de las ocupaciones del territorio.

Tierra del Fuego sería un paisaje cultural, en la medida que en su territorio se incorporaron formas antrópicas, que evidencian ciertos procesos de evolución, en un ámbito geográfico que posee valores estéticos y adquiere valores culturales, superpuestos en la forma de estratos, capas o layers en las cuales se han impreso determinados hechos sociales y económicos. A ello se añade la idea complementaria de un "paisaje cultural extremo». El paisaje sería extremo en la medida que el territorio juega un rol protagónico, sea por su clima, geología, elementos relevantes o peculiares, posición terrestre, etc., y en donde las formas antrópicas han interpretado y modificado dicho territorio mediante las formas de vida, las exploraciones y viajes, los circuitos, el dominio territorial, las obras de infraestructura y arquitectura, etc. La palabra extremo nos remite a un concepto que posee magnitudes, escalas, complejidades, grados de dificultad, etc., con características de confín prístino, remoto, distante, intenso, excesivo, espontáneo, etcétera.
La definición de paisaje cultural extremo se aplica a Tierra del Fuego en función de: 1) Sus paisajes singulares; 2) Un corpus de narraciones y cartografías que forman los testimonios de navegantes, viajeros y científicos que la exploraron; 3) La muy interesante cultura aborigen de los sélknam que la poblaron aproximadamente desde e año 11.000 AP.; y 4) Los hechos territoriales de una colonización económica -basada en la explotación de sus recursos naturales-que se llevó a cabo desde fines del siglo xIX con la fundación de asentamientos humanos y la formación de company lands relacionados con la colonización pastoril y la explotación de hidrocarburos.

\section{Los paisajes extremos en Tierгa del Fuego}

La Tierra del Fuego es la mayor isla del continente americano. Debe su nombre al hecho que durante el viaje de exploración de estrecho que lleva su nombre, Hernando de Magallanes y su tripulación habrían visto gran número de fogatas en las costas al suroriente del estrecho, probablemente a la cuadra de las actuales Primera o Segunda Angostura. Anne Chapman ${ }^{12}$ indica la posibilidad de que los sélknam, divisadas esas embarcaciones, hubiesen encendido las fogatas como medio de comunicación de largo alcance para avisar a otros miembros de su haruwen de la presencia de las extrañas naves. Esos fuegos habrían sido vistos por la tripulación de las naos y de allí la denominación. Otra posibilidad es que los fuegos avistados fuesen fuegos fatuos asociados con la combustión espontánea de bolsones superficiales de gas, cuya existencia fue comprobada unos 430 años después, con el hallazgo de petróleo y gas natural por Enap en la Isla.

Tierra del Fuego está ubicada aproximadamente entre el paralelo cincuenta y dos y el paralelo cincuenta y cinco de latitud sur, latitud en la que es el único lugar poblado de la tierra en forma permanente, junto con la isla Navarino. Es una manifestación compleja y extrema del ámbito mayor de la Patagonia Magallánica. Está limitada por el Estrecho de

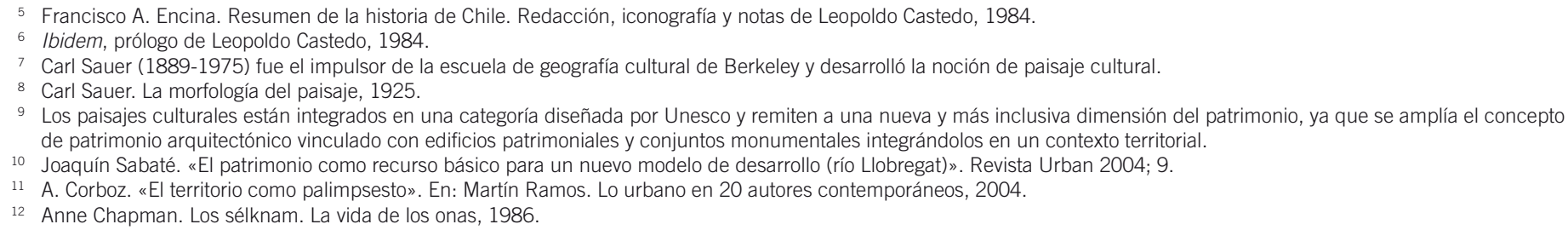


Magallanes, el canal Beagle, el mar de Drake, el océano Atlántico y el océano Pacífico. Posee una topografía caracterizada por sus amplias Ilanuras centrales, con cierto relieve, que dan lugar hacia el sur a la presencia de unos desmembrados Andes patagónicos, con el nombre de cordillera de Darwin. El clima está definido por los fuertes vientos, la presencia constante de la lluvia y la nieve, el soleamiento escaso y oblicuo, los cielos siempre cambiantes.

Su extensión es como un círculo del cielo donde el horizonte establece a la redonda la vastedad de los límites y referencias visuales que la dotaron de sus cualidades estéticas ${ }^{13}$. Posee unos paisajes conformados con elementos geográficos, disímiles y contrapuestos, armónicos y complementarios, de una geografía evidentemente loca que se encuentra más allá del final de nuestra angosta faja de tierra, donde coexisten, entre otros elementos, lagos y cordilleras, glaciares y praderas, bosques y estrellas, crepúsculos prolongados con cielos tormentosos y cambiantes y sombras muy largas y un ámbito insular con límites en dos océanos, un mar, un canal y un estrecho... Sus paisajes extremos comprenden el extraordinario contorno de sus costas, rico en bahías, fiordos, canales, senos, cabos, ventisqueros, y lugares tan significativos como el sitio Ramsar en bahía Lomas, las praderas ventosas del norte de la Isla, las tierras bajas comprendidas entre bahía Inútil y bahía San Sebastián, la sierra Carmen Sylva, los grandes cuerpos de agua del lago Blanco y lago Lynch, los bosques de lenga rojos en otoño, el cordón de La Paciencia presidido por el cerro Diamante, la falla geográfica compuesta por el seno Almirantazgo, el río Azopardo y el lago Fagnano, la cordillera de Darwin, la bahía Yendegaia -coronada al oriente por los montes Pirámides- que se abre sobre el canal Beagle, entre muchos otros.

La Isla es compartida por Chile y Argentina, países a quienes les corresponde la sección occidental y oriental, respectivamente, de acuerdo con el Tratado de Límites de 1881, que estableció como frontera una línea recta norte-sur que va desde el cabo Espíritu Santo hasta el eje del canal Beagle. El Tratado otorgo una superficie (aproximada) de 2.948 .000 hectáreas para Chile y 1.850 .000 hectáreas para Argentina.

\section{Los exploradores europeos}

Desde Pigafetta a Darwin, desde Sarmiento de Gamboa a Gusinde ${ }^{14}$, la Tierra del Fuego ha sido explorada desde su primer avistamiento por Hernando de Magallanes, quién el 1 de noviembre de 1520 dio con el estrecho que lleva su nombre, vía de unión entre los océanos Pacífico y Atlántico y de separación del continente americano con Tierra del Fuego, esa terrae incógnita que se despliega hacia el sur y el este. Pedro Sarmiento de Gamboa, en 1584, impulsó la fundación de asentamientos humanos en el estrecho, con dos establecimientos llamados Nombre de Jesús y Rey Felipe, ambos fracasados después de años de enormes dificultades que llevaron a la muerte a sus trescientos habitantes por falta de provisiones, hecho que Rey Felipe sea conocido hoy en día con el significativo nombre de Puerto Hambre ${ }^{15}$.

En 1616, los holandeses Le Maire y Schouten descubrieron el Cabo de Hornos y confirmaron la conjetura de navegantes españoles y de Francis Drake, quién en 1579 propuso la idea de que Tierra del Fuego era una isla que formaba parte de un complejo archipiélago. Desde entonces se sucedieron numerosas expediciones, entre ellas la de Phillip Parker King, quién dirigió importantes trabajos hidrográficos entre 1826 y 1830, encargados por el almirantazgo británico, en el litoral chileno de la Patagonia y la Tierra del Fuego. Otro británico, Charles Darwin exploró Tierra del Fuego y territorios adyacentes entre 1832 y 1834 en la nave Beagle, al mando del capitán Robert Fitz Roy. Darwin describió el sur de Tierra del Fuego como «un país montañoso, en parte sumergido, de tal suerte que profundos estrechos y vastas bahías ocupan el lugar de los valles... En este clima... la atmósfera parece más sombría que en todas partes... los numerosos canales que se hunden en la tierra, entre las montañas, revisten matices... que parecen conducir fuera de los límites de este mundo» 16

Cincuenta años después, en 1886, arribó a Tierra del Fuego otro expedicionario europeo, el rumano Julius Popper ${ }^{17}$, quién fue el primero en recorrer el interior de la Isla (muy diferente por cierto al país montañoso descrito por Darwin desde sus costas del sur), entre la bahía Porvenir y la bahía San Sebastián, donde descubrió y organizó el yacimiento aurífero denominado El Páramo, en cuya cercanía propuso la fundación de un pueblo marítimo que denominó Atlanta ${ }^{18}$. Fue un adelantado en la campaña de exterminio de los aborígenes y ya es un clásico la fotografía en la cual aparece un sélknam muerto al pie de sus batidores. Otro europeo de origen ruso, Mauricio Braun, radicado en Punta Arenas, fue el encargado de organizar y administrar como director-gerente, desde 1893, a la Sociedad Explotadora de Tierra del Fuego, formada a partir de una Concesión de Tierras ${ }^{19}$ que superó el millón de hectáreas. La Sociedad es considerada pionera en relación con la explotación económica de la Isla en base a las estancias ovejeras. José Menéndez, originario de Miranda de Avilés, Asturias, llegó a Punta Arenas en 1874 y se inició en el negocio ovejero transportando a los animales desde las islas Malvinas, lugar donde la crianza de ovinos había sido exitosa. Creó una importante empresa ganadera, con estancias formadas tanto en el continente (San Gregorio) como en Tierra del Fuego (Primera y Segunda Argentina).

Unos años más tarde, el sacerdote salesiano italiano Alberto De Agostini, llegado a Punta Arenas en 1910, aportó de manera significativa a la exploración de las cordilleras patagónica y fueguina y al conocimiento de la región austral, mediante fotografías, libros, películas y cartografías, entre ellas el plano de Tierra del Fuego impreso por la Soc. Cartográfica F. De Agostini de Milano (1959), que se difundieron en Europa. En 1955, a la edad de setenta y dos años, dirigió la ascensión del monte Sarmiento, el más alto la Isla, con 2.404

13 Sobre la «vastedad», ver: José Ricardo Morales. Arquitectónica, 1984; pp. 173 y siguientes.

14 Antonio Pigafetta. Relazione del primo viaggio intorno al mondo, 1928; Charles Darwin. Darwin en Chile (1832-1835), 1996; Pedro Sarmiento de Gamboa. Viajes al Estrecho de Magallanes 1579-1584, 1950; Martín Gusinde. Feuerland Indianer, 1931.

15 El lugar fue denominado Port Famine (Puerto del Hambre) por el corsario inglés Thomas Cavendish al visitar el asentamiento español abandonado.

16 Charles Darwin, op. cit., p. 63 en adelante. Recordemos que las descripciones de Darwin fueron realizadas muchas veces desde la Beagle y sus excursiones a tierra no incluyeron el interior fueguino.

Una versión novelada de la vida de Popper es El corazón a contraluz, 1996, extraordinaria novela de Patricio Manns.

18 Julius Popper. Atlanta, 2003

19 El sistema de Concesiones de Tierras fue adoptado por los gobiernos del presidente Santa María (1881-1886), del presidente Balmaceda (1886-1891) y continuadores, como forma de entregar a empresas y sociedades ganaderas en arriendo las tierras fueguinas por plazos de hasta 25 años. Las principales Concesiones fueron otorgadas en $1885-$ $1916,1916-1928$ y 1938-1941. 


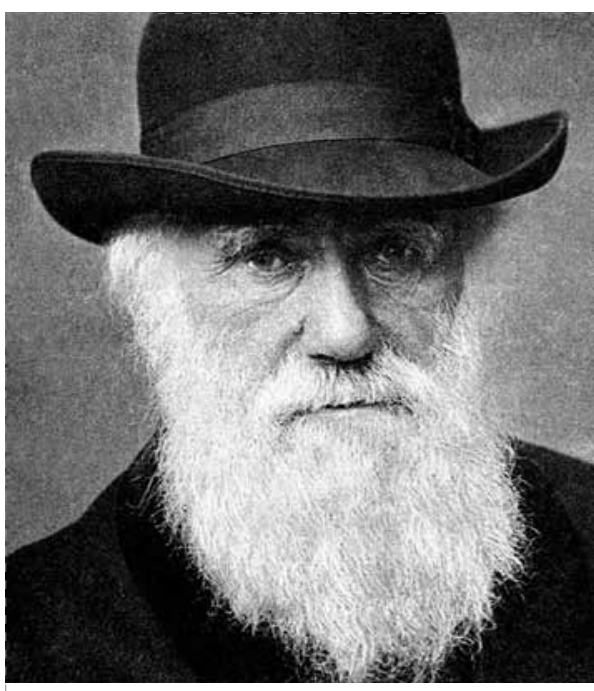

Charles Darwin (fuente: wWw.google.com)

metros de altura ${ }^{20}$. El sacerdote austríaco Martín Gusinde, de la congregación del Verbo Divino, llegó a Chile en 1912. Realizó cuatro expediciones a Tierra del Fuego, entre 1918 y 1923, y consiguió convivir intensamente con sélknam y yámanas para ganar su completa confianza y participar en una ceremonia del Hain ${ }^{21}$. Durante estas expediciones obtuvo el material fotográfico y etnológico para la publicación de su obra capital, Feuerland Indianer (1931), traducida al castellano como Los Indios de la Tierra del Fuego22.

La cartografía de la región Magallánica y Tierra del Fuego supera las dos mil piezas, cantidad impresionante de representaciones que informa de los conocimientos cartográficos de cada época así como de los mitos y leyendas que se tejieron en relación con la Isla y sus áreas de influencia. El interés de los diversos países europeos por cartografiar el área meridional de América se explica por la importancia estratégica del Estrecho de Magallanes y la ruta del Cabo de Hornos para la navegación mundial, hasta la apertura del canal de Panamá en 1914. Esta cartografía incluye piezas arcaicas, como el sector del Planisferio denominado Padrón Real de Turín de 1523, y planos modernos, como el plano de Tierra del Fuego a escala 1: 2.250.000,

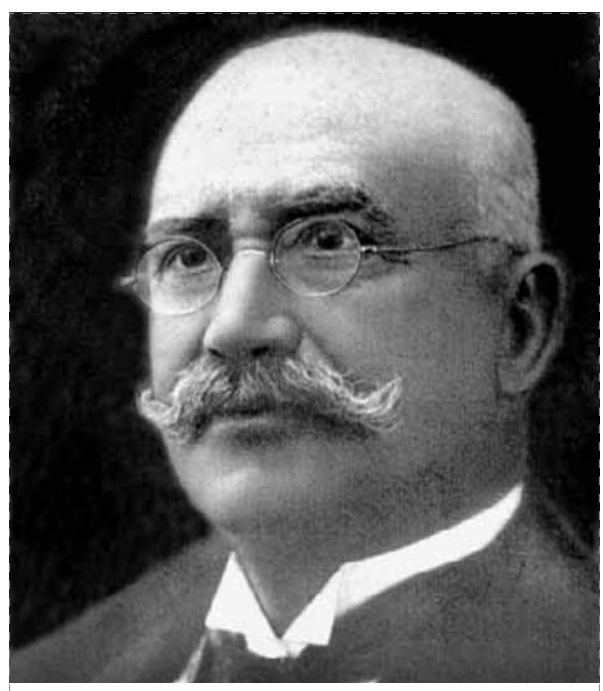

José Menéndez

(fuente: wWw.google.com)

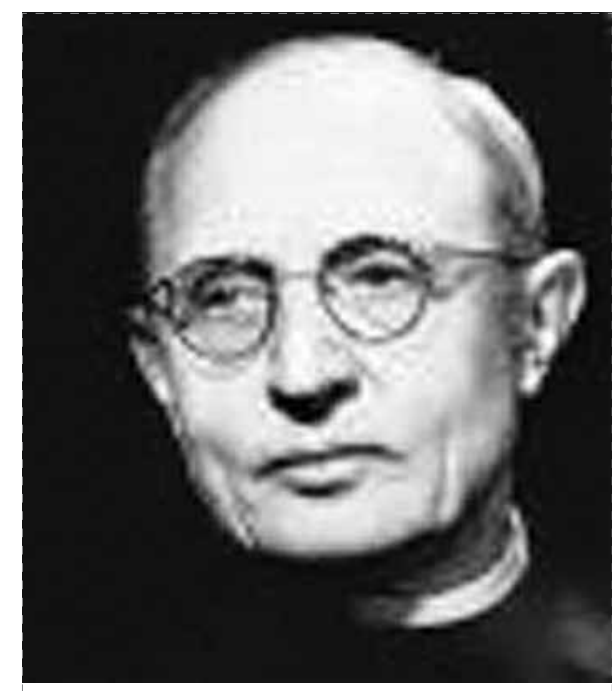

Martín Gusinde (fuente: www.google.com)

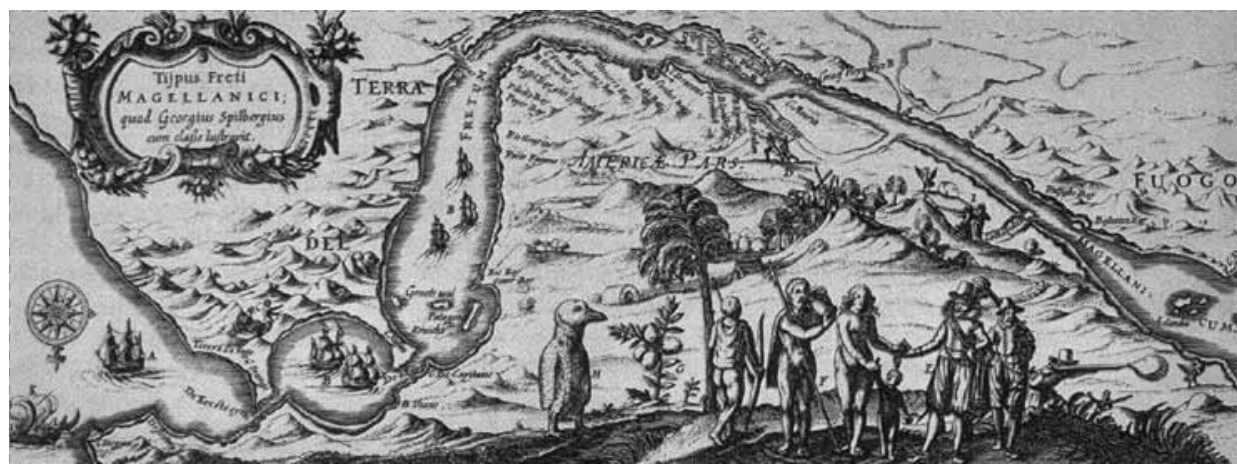

Plano de Van Spilbergen, 1614-1619 (fuente: Martinic: Cartografía Magallánica 1523-1945)

impreso por F. De Agostini en 1959. Incluye entre otros los mapas de Santa Cruz (1540), Van Spilbergen (1614), Arellano (1619), Gerritz (1622), Keer (1645), Gotha $(1887)^{23}$.

\section{La cultura aborigen}

de los sélknam

Tierra del Fuego fue durante cerca de ciento diez siglos la patria de los aborígenes conocidos como sélknam (onas), un pueblo de individuos físicamente muy bien conformados que con el tiempo desarrolló una adaptación extraordinaria a las duras características geográficas y ambientales de Tierra del Fuego ${ }^{24}$. El nomadismo les permitió desplazarse en procura de los alimentos necesarios para su existencia, con la práctica de la caza y la recolección de frutos. El guanaco, animal esencial en su economía como lo fue el bisonte para los indígenas de las praderas

20 Ver: De Agostini, Alberto, Esfinges de Hielo, 1959

${ }^{21}$ La ceremonia del Hain era el rito de iniciación de los adolescentes sélknam.

22 La traducción al castellano fue realizada por el Centro de Etnología Americana de Buenos Aires, 1982.

23 Ver: Cartografía Magallánica 1523-1945, 1999 de Mateo Martinic. Premio Nacional de Historia y coinvestigador de la investigación Fondecyt «Las formas de ocupación del territorio en Tierra del Fuego", 2005, en que se basa este artículo.

24 Tenían una especial adaptación metabólica, con temperatura corporal un grado superior a la nuestra y una estatura promedio de 1,80 m. 
Plano de Santa Cruz, 1540

(fuente: Martinic: Cartografía Magallánica 1523-1945).

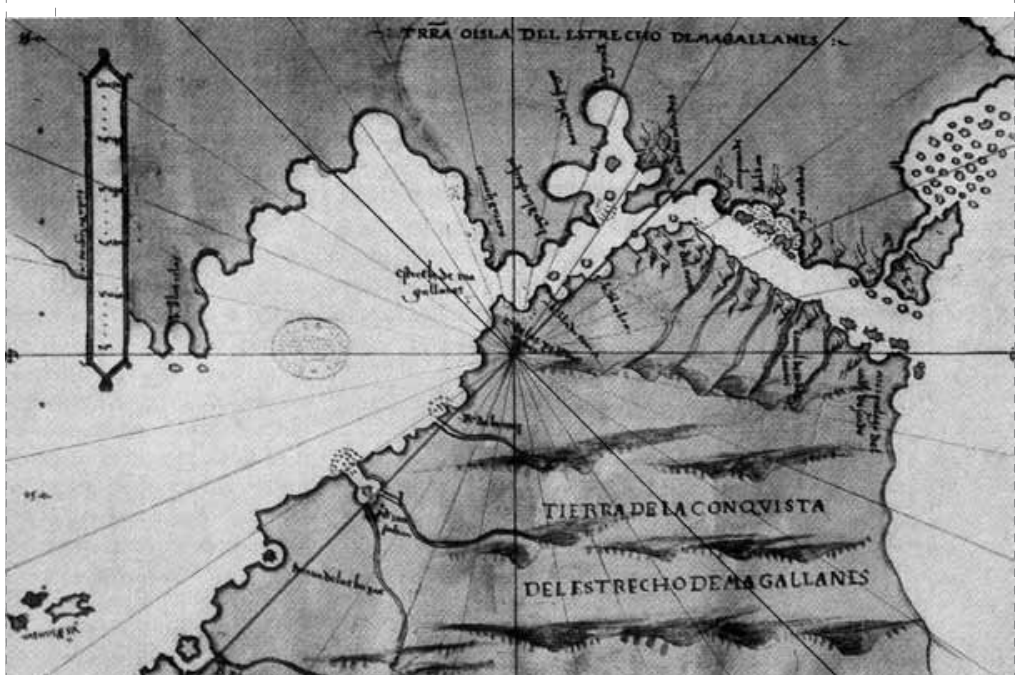

Plano de Tierra del Fuego. De Agostini, 1959

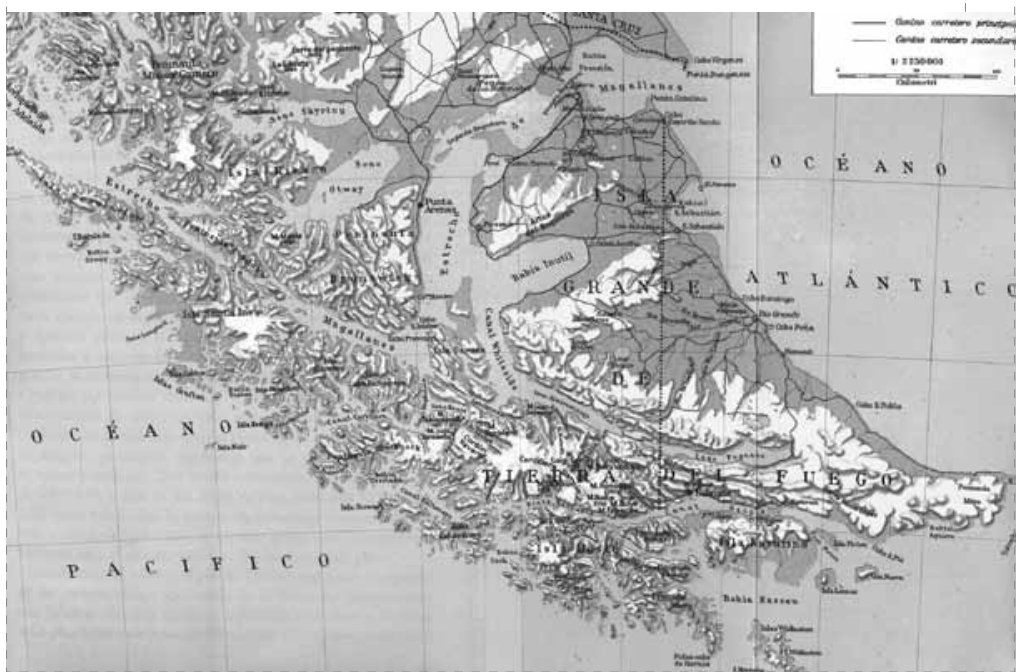

norteamericanas, les brindaba carne para su alimento y pieles para su vestimenta, los usos artesanales y la cubierta de sus chozas.

En tanto expresión de arquitectura, las chozas se basaron en una estructura de ligeras varas que las mujeres sélknam portaban durante las excursiones, como base de una construcción resistente a los fuertes vientos, que se completaba con varas más robustas, si las había a mano, forradas exteriormente con pieles, cortezas y ramas, dejando una apertura superior para la salida del humo y otra, en dirección opuesta del viento dominante, para ser utilizada como puerta. Un entrelazado de ramas y hojas se empleaba como cubierta del suelo. La posición del fuego y la distribución del calor organizaban su disposición semicircular.

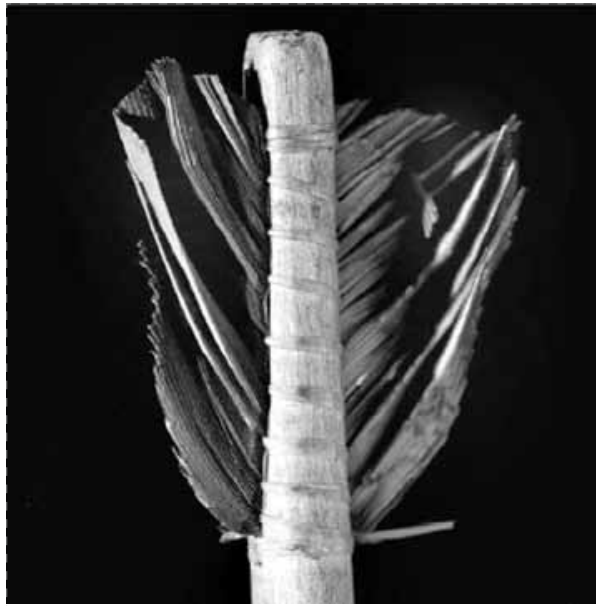

Emplumadura de una flecha sélknam (fuente: A. Prieto).

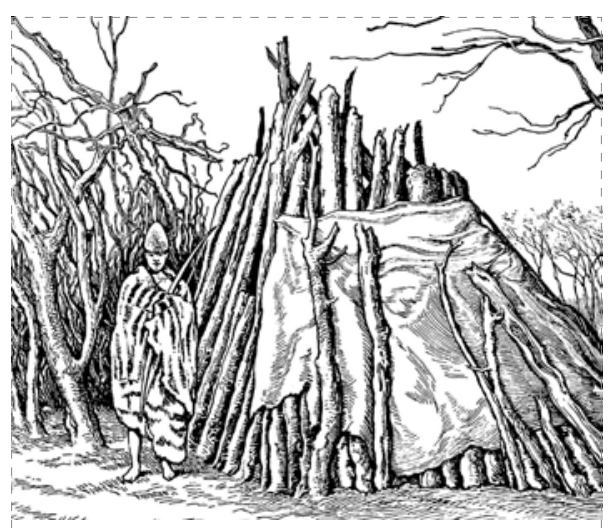

Choza sélknam del norte.

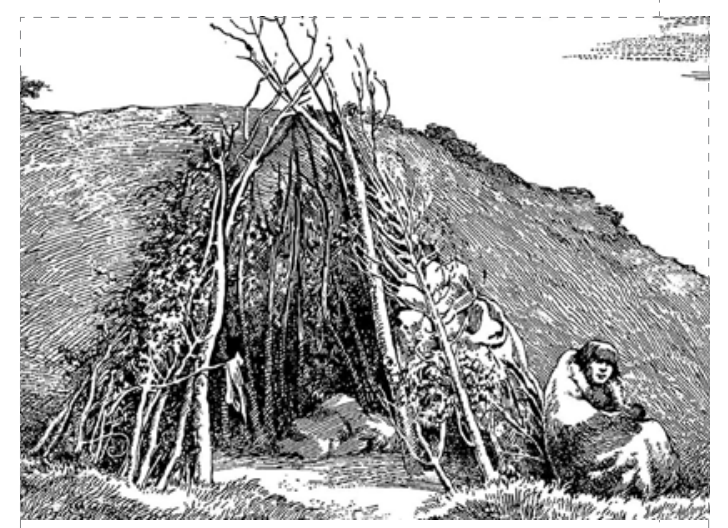

Choza sélknam del sur.

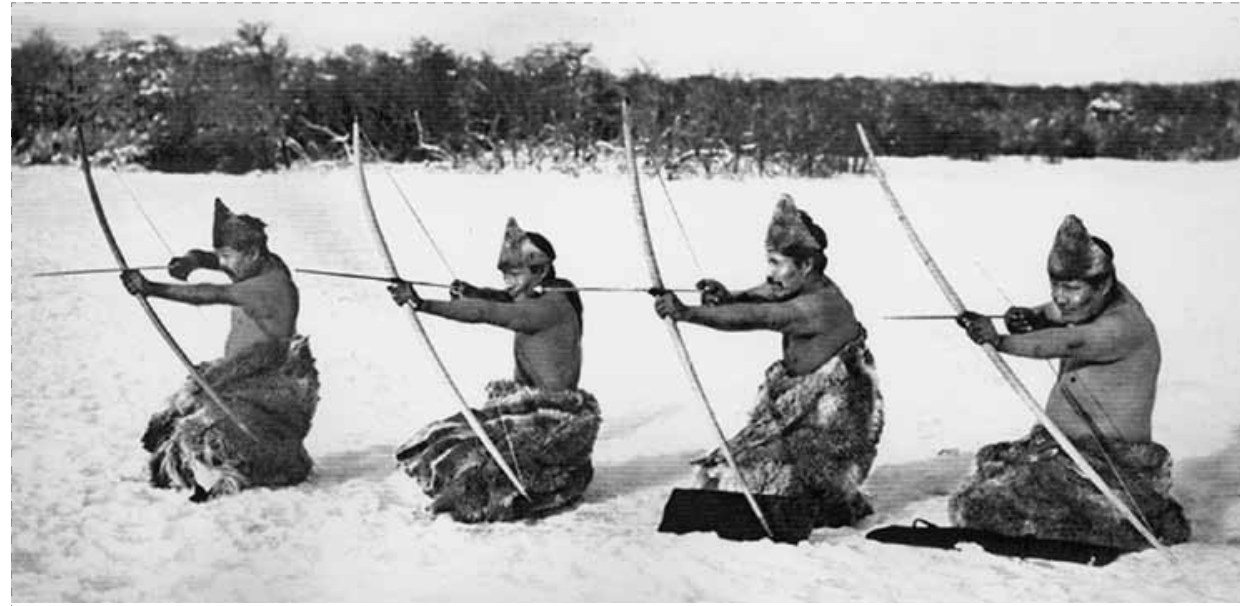

Fotografía de arqueros sélknam en posición de tiro

(fuente: Gusinde, 1923). 
Familia sélknam (fuente: Gusinde, 1923).

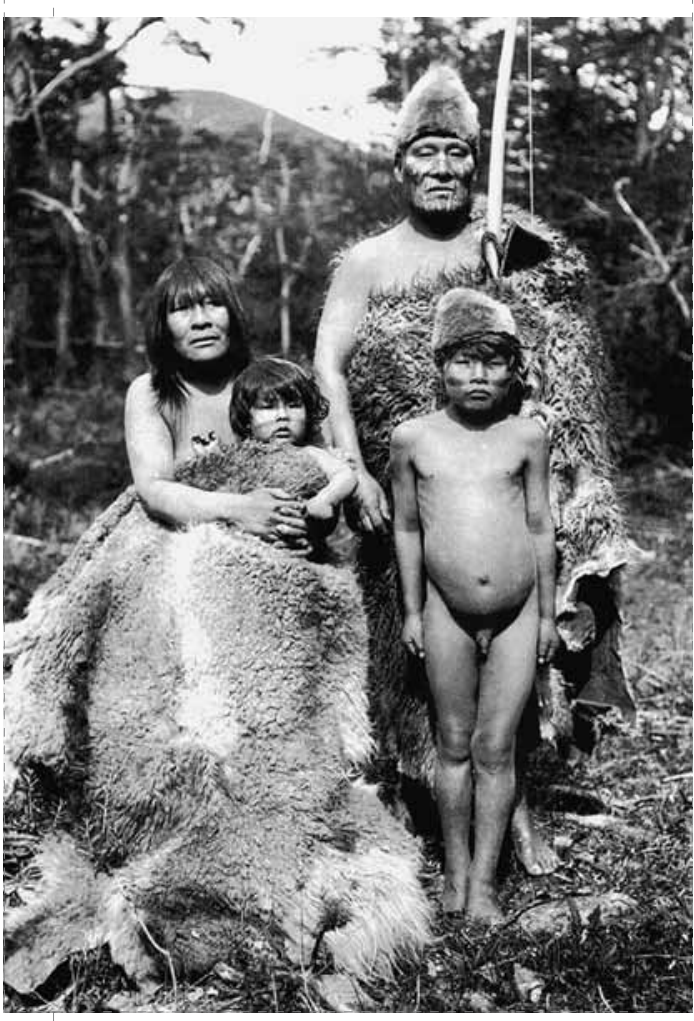

Fotografía de participantes en la ceremonia Hain (fuente: Gusinde, 1924).

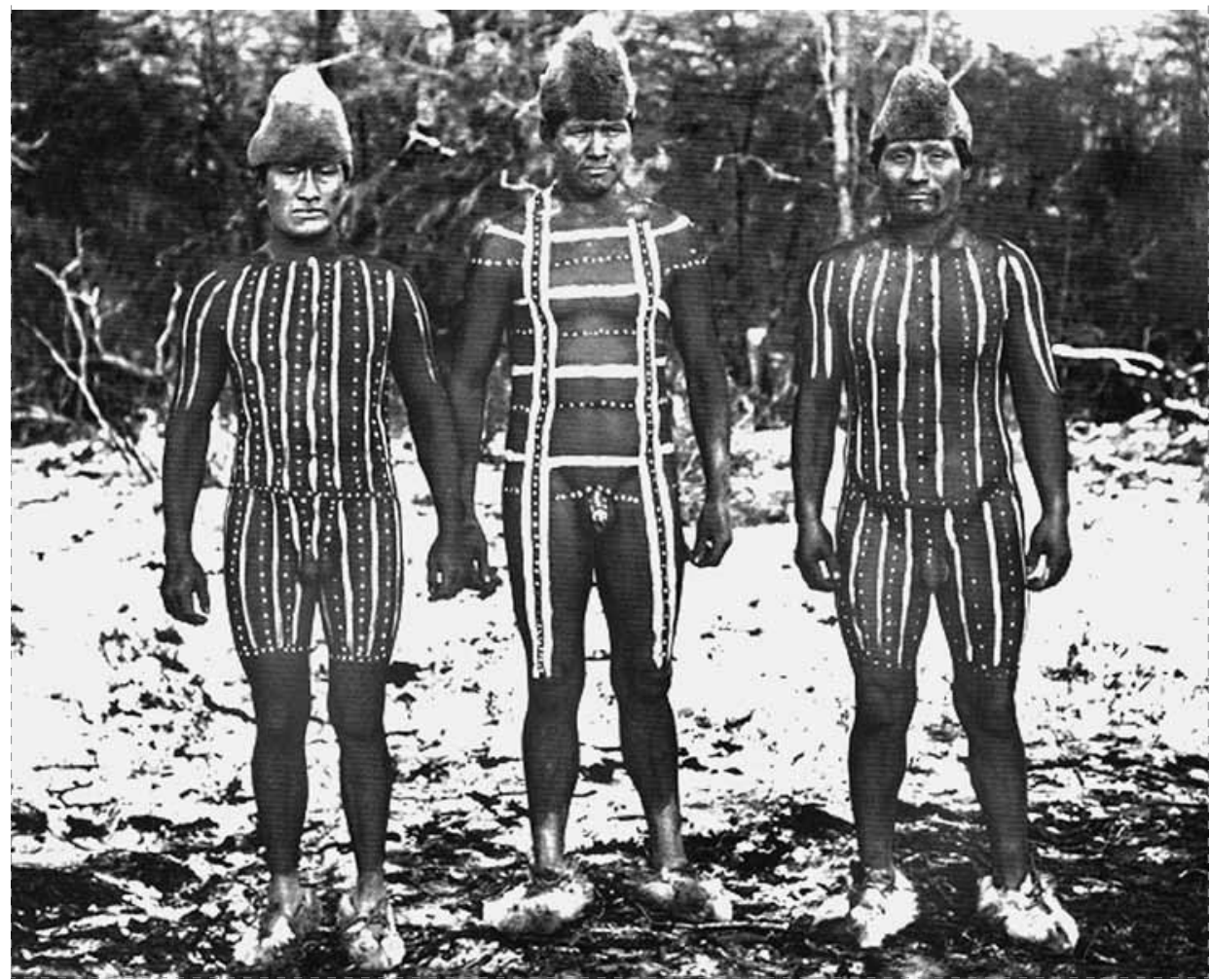

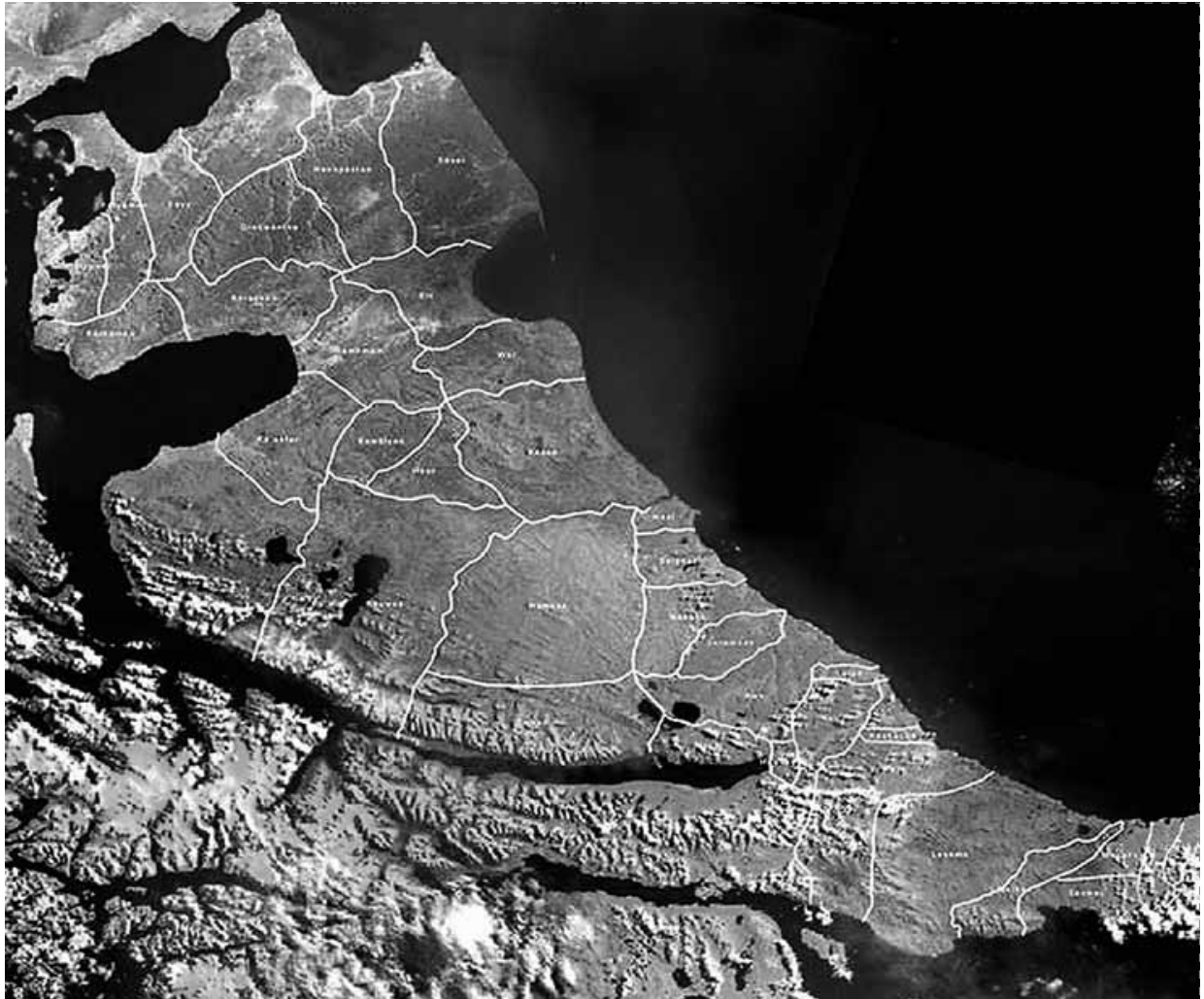

Distribución de háruwen según Gusinde sobre fotoplano NASA (fuente: Garcés y otros, 2005).
Considerando que se trata de unos aborígenes cazadores y recolectores, las armas empleadas en las cacerías son muy importantes. El arco, pieza de notable artesanía, y la flecha, objeto de depurado diseño y construcción, son centrales en su economía. La emplumadura del astil se disponía de modo tal que propulsaba la flecha en giro rotatorio, necesario para producir un mejor vuelo rectilíneo y lograr una mayor eficiencia en las cacerías ${ }^{25}$.

Por su parte, la vida espiritual de los sélknam era muy rica. Estaba conformada por un corpus de dogmas y tradiciones acerca del origen de su sociedad, el mundo natural, las normas de comportamiento y los patrones de relación entre sus miembros, con el entorno y sus recursos. La ceremonia del Hain formalizaba el rito de iniciación de los jóvenes en esas tradiciones originarias, místicas y mitológicas ${ }^{26}$

El dominio del territorio lo conseguían mediante la institución del háruwen que destinaba a cada grupo familiar la explotación exclusiva de ciertas áreas geográficas muy

Alfredo Prieto. El arco y la flecha de los sélknam, 2008.

Carlos Keller. Dios en Tierra del Fuego, 1947 
bien demarcadas en relación con accidentes topográficos, curso de ríos, imprecisas señales de la llanura, etc., cuyos límites exigían una estricta observancia, por lo que su conocimiento era comunicado de generación en generación ya que su violación era causa de disputas entre linajes. El tamaño de cada háruwen dependía del grado de productividad que brindara, de manera que una zona rica en recursos exigía un háruwen menor y viceversa. Cada una de estas áreas era habitado por el linaje correspondiente a un grupo de parientes consanguíneos que por vía patrilineal los unía a anteriores generaciones.

El háruwen también respondía a una cuestión espiritual, asociada con el cosmos. De acuerdo con la mitología sélknam, Kenós fue enviado por Timaukel para crearlo y repartió a cada linaje una porción de terreno claramente establecida, perteneciente a una unidad mayor denominada cielo. En cada háruwen se representaban los antepasados de manera que cada río, lago, monte, pradera, bosque, fue anteriormente un sélknam el que al morir escogió transformarse en un cierto elemento del territorio, dando forma a la tierra y el cosmos. El hecho de que el háruwen estuviera delimitado por la corporización de un antepasado establecía un vínculo entre hombre y mundo y complementaba el habitar del territorio extremo con una dimensión espiritual. Existían cuatro cielos (shó'on), a los cuales pertenecían todos los háruwen, referenciados por los puntos cardinales, los que unidos representaban la totalidad del cosmos y agrupaban a la estructura social sélknam. Cada miembro de un linaje pertenecía desde su nacimiento a un háruwen y por consiguiente a un shó'on establecido. En caso de un matrimonio, era la mujer la que debía trasladarse, dejando su háruwen y su shó'on, pasando a formar parte del de su marido 27 .

Martín Gusinde ${ }^{28}$, dibujó un plano de los háruwen a partir de la interpretación de una información transmitida oralmente. De acuerdo con este plano, los háruwen eran treinta y ocho para una población de tres mil ochocientos individuos, hacia mediados del siglo xIX; según estudios posteriores de Anne Chapman ${ }^{29}$, los háruwen eran ochenta. Investigaciones más recientes establecen una densidad ocupacional de un habitante por cada veinticinco kilómetros cuadrados de territorio, cifra que sugiere una población de mil quinientos individuos para toda la Isla ${ }^{30}$.

El otorgamiento de las mencionadas Concesiones de Tierras dio origen al exterminio de los sélknam por individuos perfectamente armados, entrenados y remunerados. Los indígenas que no murieron en las batidas fueron confinados en las misiones salesianas de San Rafael y Río Grande donde las enfermedades europeas de contagio acabaron con esta espléndida raza. La última sélknam, Ángela Loij, falleció en 1974.

\section{Los hechos terгitoriales de la colonización económica}

En Chile existen una serie de territorios extremos situados en los márgenes de la experiencia cotidiana de sus habitantes. Cuando la explotación de sus recursos naturales ha resultado rentable, la construcción de asentamientos humanos permite habitarlos. Es el caso de los campamentos de la minería del cobre, situados en las alturas de la cordillera de los Andes, de las oficinas salitreras, situadas en e desierto de Atacama, y de los asentamientos del carbón, situados en el golfo de Arauco ${ }^{31}$. Es el caso de los asentamientos ganaderos y mineros que surgieron en Tierra del Fuego.

Tierra del Fuego es paisaje y es recurso ${ }^{32}$. En cuanto recurso, debe su existencia a un proceso productivo que la transformó en producto, activado por los grupos humanos que allí se asentaron y se sustentan; en cuanto paisaje ${ }^{33}$, ha sido formada por la relación intensa entre los valores, ideales, nostalgias, esperanzas, ambiciones humanas sobre el soporte geográfico de Tierra del Fuego. Desde fines del siglo XIX, se desarrolló un conjunto de asentamientos humanos que surgieron a raíz de una colonización económica basada en la explotación de sus recursos naturales -oro pradera, petróleo, paisajes- cuya expresión territorial son los company lands ${ }^{34}$ agrarios y minero, produciendo obras conjuntas del hombre y la naturaleza que ilustran las diversas formas con que éstos se establecieron en el territorio fueguino y dominaron su ambiente extremo con finalidades productivas.

La noción de company land representa la idea de una región activada en términos empresariales mediante la construcción de instalaciones industriales, asentamientos humanos, infraestructuras viaria y portuaria entre otros, de manera tal que todos los elementos resultan interdependientes entre sí para conseguir el funcionamiento del conjunto como un gran espacio industrial. En este sentido, tanto la ocupación ganadera de Tierra del Fuego, en la forma de grandes sociedades ${ }^{35}$ que administraban a las estancias ganaderas ${ }^{36}$, así como la ocupación

27 Alumnos Croxatto y Vial. «El viaje de Martín Gusinde y el habitar de los sélknam que configura el territorio extremo de Tierra del Fuego». En: Taller de Investigación $2^{\text {do }}$ Semestre 2008. Profesores Eugenio Garcés Feliú y Franz Kroeger.

28 Martín Gusinde. Expedición a Tierra del Fuego, 1980.

29 Anne Chapman, op. cit., 1986.

30 Clara García Moro. «Reconstrucción del proceso de extinción de los sélknam a través de los libros misionales». En: Anales del Instituto de la Patagonia, 1987.

31 Sobre el tema ver: Eugenio Garcés Feliú et al. Las ciudades del cobre, 2007; Eugenio Garcés Feliú. Las ciudades del salitre, 1999. En relación con Lota, ver: Leonel Pérez. Tesis Doctoral: La mirada y la memoria, 2007.

32 Respecto del territorio - paisaje y recurso- se puede revisar una abundante bibliografía. Entre otros, ver: Manuel Solá-Morales. «Reconocimiento comarcal y ordenación del territorio». Revista Quaderns Extra Nos 1 y 2 s/f; Vittorio Gregotti. El territorio de la arquitectura; César Naselli. «El paisaje territorial». Revista MW 2007, № 9; Mª del Milagro Escribano et al. El paisaje, 1991

33 De acuerdo con Cesar Naselli, op. cit., el paisaje «es un constructo cultural, interdisciplinar, producto de un imaginario y de una conceptualización de la realidad, que adquiere un valor de objetividad tal, que lo convierte en un modelo de dicha realidad para el observador que lo construye, a través de su cultura y capacidades, y de la instrumentalización de su aparato cognoscitivo». Para Cristina Felsenhardt («Naturaleza, paisaje y paisajismo». Revista CA 2001; 106), el paisaje: «no se encuentra sólo en el objeto, sino en la mirada; no es lo que está, sino lo que se ve..". Vittorio Gregotti en El territorio de la arquitectura (1972), se lee que el paisaje debe su existencia a un "proceso operativo humano, construido históricamente sobre un determinado soporte geográfico que lo ha construido paciente y coherentemente».

34 La noción de company land surgió como complemento y extensión de company town. En: Taller de Investigación 2 ${ }^{\text {do }}$ Semestre 2008. Profesores Eugenio Garcés Feliú y Franz Kroeger.

35 Las sociedades «pioneras» fueron: Wehrhahn y Cía. (120.000 há), The Tierra del Fuego Sheep Farming Co. (180.000 há), The Philip Bay Sheep Farming Co. (170.000 há), Sociedad Explotadora de Tierra del Fuego (SETF) (1.009.000 há) y Sociedad Industrial y Ganadera de Magallanes (190.000 há).

36 Las principales estancias en Tierra del Fuego son: Gente Grande (1885), Springhill (1890), Caleta Josefina (1893), Bahía Felipe (1896), Cameron (1904), Vicuña (1915), Russfin (1920), China Creek (1924) 
petrolera desarrollada por la Empresa Nacional del Petróleo (ENAP) ${ }^{37}$ para la explotación de los hidrocarburos, constituirían formas de company lands.

Los company lands agrarios surgieron hacia 1880, cuando se formaron en Punta Arenas sociedades ganaderas para postular a las mencionadas Concesiones de Tierras. Éstas fueron otorgadas, para el período 1885-1915 a las sociedades Wehrhahn y Cía. (120.000 há), The Tierra del Fuego Sheep Farming Co. (180.000 há), The Philip Bay Sheep Farming Co. (170.000 há), Sociedad Explotadora de Tierra del Fuego (Setf) (1.009.000 há) y Sociedad Industrial y Ganadera de Magallanes (190.000 há). El otorgamiento de estas concesiones implicó una primera ordenación del territorio, en cinco enormes predios, dando paso a una estructura de company lands agrarios que lo activaron en términos productivos a partir de las estancias ganaderas ${ }^{38}$. Datos de $1907^{39}$ indican que la Isla, a 20 años de la primera etapa de las Concesiones, había sido transformada en un territorio productivo de importancia, ocupado por cinco empresas ganaderas, 1.626 habitantes y 750.000 cabezas de ganado ovino ${ }^{40}$

\section{Los asentamientos humanos}

\section{Puerto y campamento}

El puerto de Porvenir (4.165 habitantes) es capital de provincia, sede de la gobernación de Tierra del Fuego y del Municipio de Porvenir. Nació en 1894, por decreto supremo del presidente de Chile Jorge Montt en el sitio donde se había establecido un villorrio espontáneo surgido con la minería del oro. Está situado en la bahía Porvenir, descubierta en 1881 por el oficial de marina Jorge Porter cuando reconocía el área en busca de placeres auríferos. La exploración resultó exitosa e hizo posible el surgimiento de la minería, primera actividad económica que se llevó a cabo en Tierra del Fuego, en ambas vertientes de la sierra Boquerón y el cordón Baquedano. Las primeras construcciones de viviendas, posadas y comercios se situaron al fondo de la bahía y en las inmediaciones del "chorrillo del oro», dando origen a la primera configuración del poblado. Sin embargo, se hizo necesaria

Planta de Porvenir y bahía (fuente: Garcés y otros, 2005)
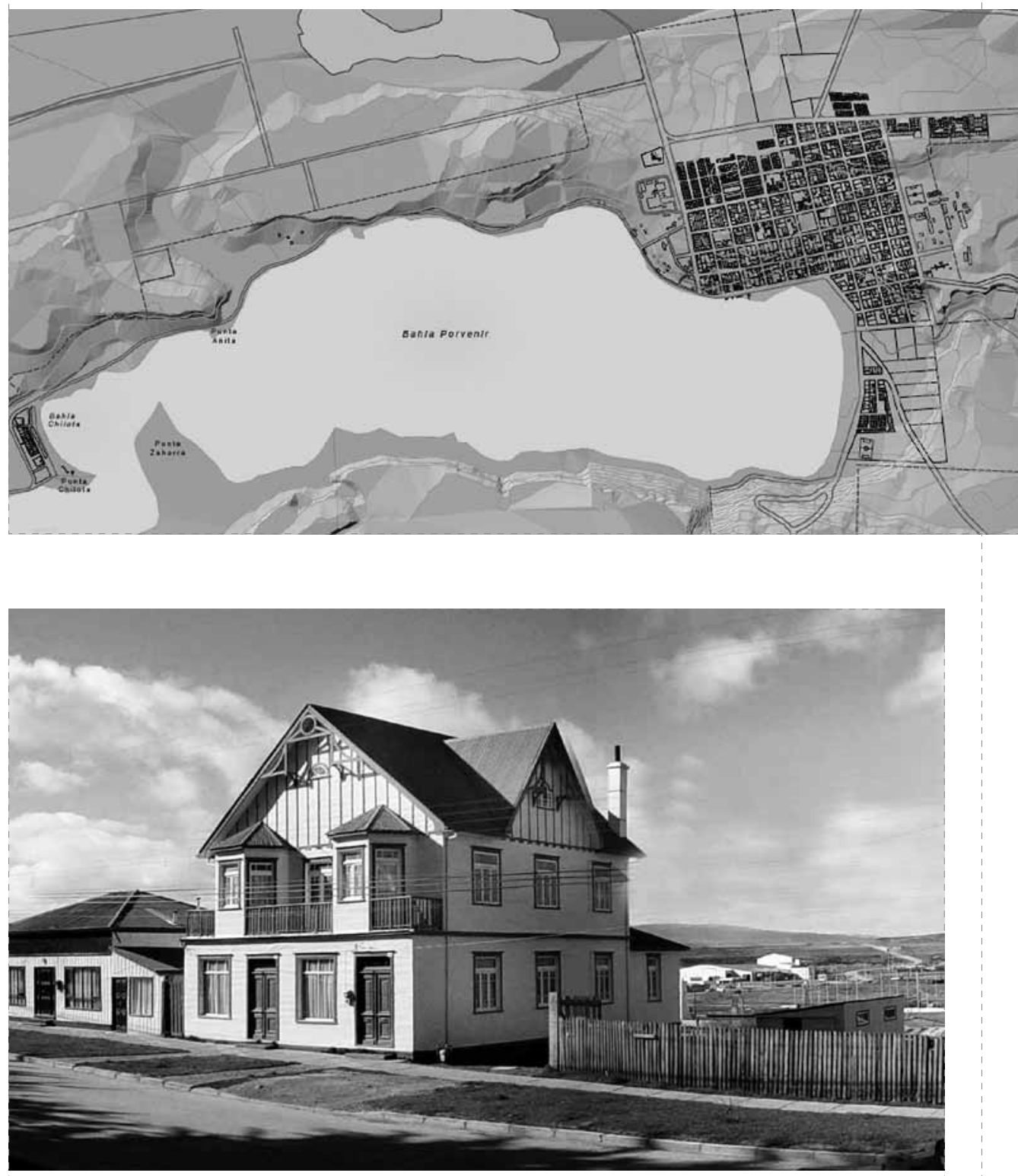

Vista de casa Mimica (fuente: Seisdedos, 2003).

una fundación más estable para afianzar la soberanía después de la firma del Tratado de Límites con Argentina (1881), organizar el campamento minero, dotar de un centro administrativo y comercial a la Isla y apoyar el naciente negocio de la ganadería ovina.
El decreto de fundación otorgó una superficie de 1.000 há para su desarrollo, obtenidas de la Concesión otorgada a la empresa ganadera Wehrhahn y Cía. Los ingenieros Aníbal Contreras y Álvaro Donoso, comisionados para realizar el proyecto

\footnotetext{
37 La Empresa Nacional del Petróleo (ENAP) fue fundada en 1950 por la Corporación de Fomento de la Producción (CORFO), para explotar comercialmente los yacimientos descubiertos en Magallanes.

38 Juan Benavides et al. Las estancias magallánicas, 1999.

39 Durante 1907 el presidente de Chile Pedro Montt visitó Porvenir.

40 Mateo Martinic. La Tierra de los Fuegos, 1980.
} 


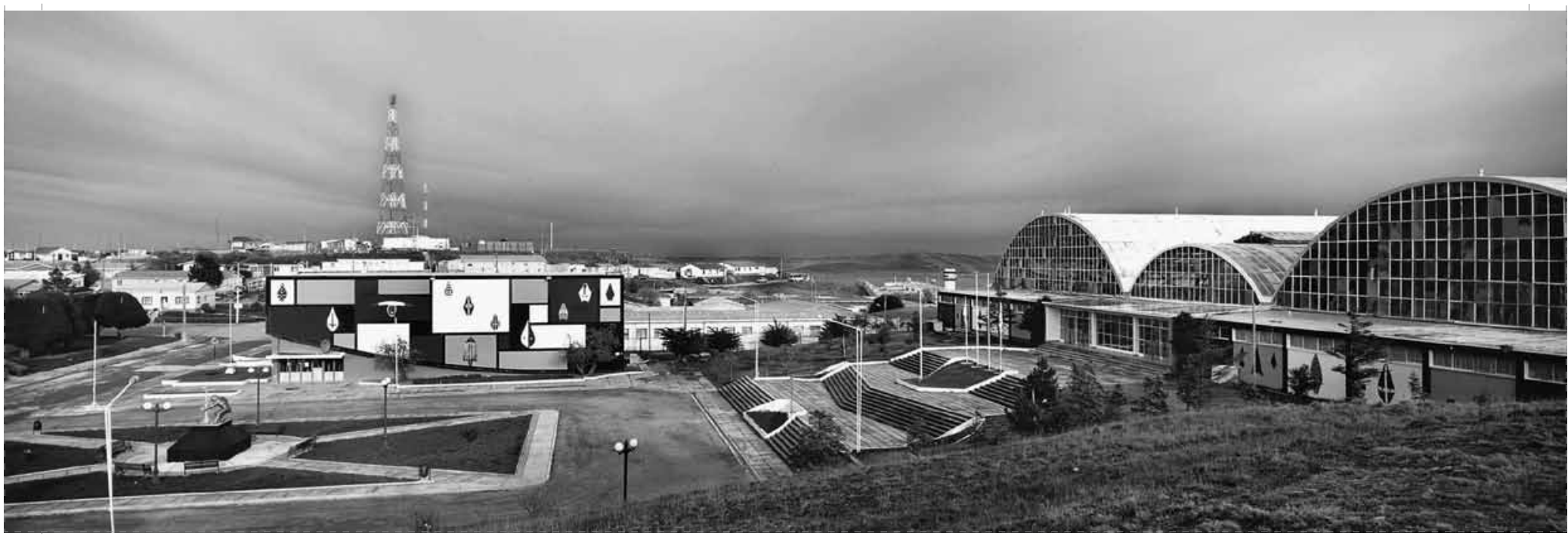

urbano, emplearon un trazado en damero de 125 metros por 125 metros a ejes de calles, con el que consiguieron regular las edificaciones ya construidas a la fecha y dar los lineamientos para las nuevas manzanas y calles. La morfología urbana se consiguió con la concentración de las edificaciones en los bordes de las manzanas, empleando el estilo pionero y patagónico ${ }^{41}$, dejando hacia el interior los huertos familiares. Se utilizó la planta de pasillo central y habitaciones laterales, con cubiertas a dos y cuatro aguas. A la vivienda de un piso se agregó la de dos pisos, ya sea aprovechando un altillo o su planta completa. Entre 1910 y 1930 se construyeron las principales viviendas, edificios públicos y comercio. Se destacan la casa Mimica, la casa Corvalán Pérez, la casa de la Cruz Roja y la casa de la Comandancia del Ejército.

El campamento ${ }^{42}$ Cerro Sombrero fue fundado por ENAP en 1958, una vez puesto en producción el primer pozo en Manantiales (1945). Fue emplazado sobre la meseta del cerro que le da su nombre, al borde del río Side, con un proyecto urbano que empleó un trazado funcional, con piezas residenciales y de equipamiento ordenadas en torno a una plaza central, configurando un company town administrativo y residencial ${ }^{43}$. Cerro Sombrero estableció un cabezal jerárquico, incorporado actualmente en un company land del petróleo, con el propósito de explotar los hidrocarburos en Tierra del Fuego y en la cuenca del Estrecho de Magallanes. En este company land concurren diversos elementos: el territorio tridimensional de explotación (tres grandes áreas en tierra adentro, borde costero y mar adentro); yacimientos y pozos para la extracción de los recursos desde el subsuelo (90 pozos en explotación que alcanzan yacimientos situados a una cota promedio de -2.500 metros); infraestructura industrial para la producción, refinamiento y exportación del gas y el petróleo (plantas de tratamiento, ductos de transporte, refinerías, puertos y terminales); e infraestructura urbana para el alojamiento de los trabajadores: Manantiales (1945), Puerto Percy (1950), Cerro Sombrero (1958) y Cullen (1962). Estos elementos interdependientes se han articulado en nodos y redes activados por sistemas y circuitos que gobiernan el funcionamiento de la empresa.

El proyecto de Cerro Sombrero incluyó 140 viviendas de distintos tipos, así como edificios de equipamiento (polideportivo, cine, iglesia, escuela, hospital, supermercado y otros) y de oficinas, todos ellos edificados con altos estándares constructivos y de habitabilidad, articulados en torno al centro cívico del campamento, uno de cuyos costados es precisamente la cima del cerro, sobre la cual se instaló un observatorio astronómico. Los edificios públicos enriquecen la vida de la población permanente, coadyuvan al desarrollo de la vida social y aseguran la identificación y sentido de pertenencia hacia una empresa del Estado, consolidando su imagen corporativa. Un edificio como el complejo polideportivo es una clara respuesta al intenso clima del lugar, que incentiva el uso periódico de sus espacios interiores como un contrapunto a la plaza cívica que preside, generando un rico diálogo entre espacio público y espacio social. En la fotografía, sin embargo, no se advierte persona alguna, hecho que discute la oportunidad de utilizar un elemento urbano como la plaza, surgida en las civitas mediterráneas, en este extremo sur. Para el diseño de las edificaciones se utilizaron libremente algunos de los elementos del estilo moderno como manera de conseguir la integración formal de cada edificio en el conjunto, empleando grandes ventanales, estructuras de hormigón y metálicas muy sencillas y volúmenes netos y sin mayor ornamento ${ }^{44}$. Actualmente, el poblado está ocupado por cerca de 600 habitantes ${ }^{45}$.

Dante Baeriswyl. Arquitectura en Punta Arenas. Casas de madera. Estas casas combinaron las características de la arquitectura centroeuropea con adaptaciones locales.

2 Su condición de "campamento» lo relaciona con otros casos como los de la minería del salitre y el cobre. Ver: Eugenio Garcés Feliú, op. cit., 2005.

43 Importantes arquitectos chilenos de la época participaron en el proyecto de Cerro Sombrero: Julio Ríos; Monckeverg, Echavarría, Briones; Jorge Searle; Bolton, Larraín, Prieto; Echenique y Cruz.

44 La fachada lateral del teatro fue pintada recientemente gracias a un proyecto Fondart con motivos de la mitología sélknam.

45 El censo de 1960, el primero donde Cerro Sombrero figura como entidad urbana, registró un total de 703 habitantes en 114 viviendas, luego durante la década de 1970 en el mejor momento del poblado llego a tener 901 habitantes en 140 viviendas. El año 1982 el registro fue de 691 habitantes. Fuentes: Martinic, Mateo, La Tierra de los Fuegos, INE: 1970,1982 
Planta de Cerro Sombrero (fuente: Garcés y otros, 2005).

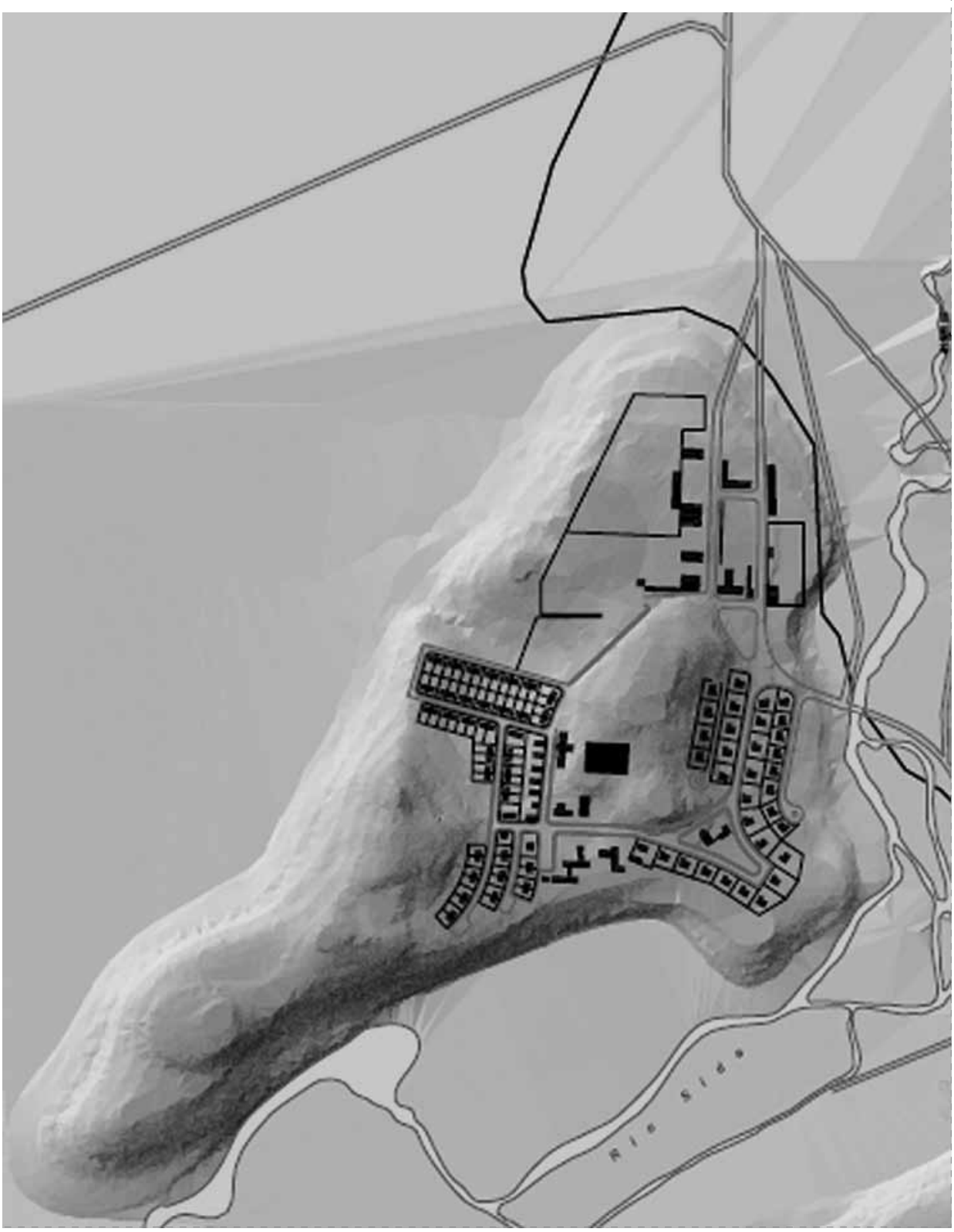

Las estancias

El otorgamiento de las concesiones en las vastas tierras situadas en el solar patrio de los sélknam implicó una primera ordenación del territorio, en cinco enormes predios, dando paso a la estructura de company lands agrarios que lo activaron en términos productivos ${ }^{46}$. Datos de $1907^{47}$ indican que la sección chilena de la Isla, a 20 años de la primera etapa de las Concesiones, había sido transformada en un territorio productivo de importancia, ocupado por cinco empresas ganaderas, 1.626 habitantes y 750.000 cabezas de
46 Juan Benavides et al. Las estancias magallánicas.

Durante 1907 el presidente de Chile Pedro Montt visitó Porvenir.

48 Mateo Martinic. La Tierra de los Fuegos.

49 Mateo Martinic. Ibid. p. 96

50 La mayoría fueron producidas en factorías de Wolverhampton y Emubrand, Inglaterra.

51 Las dimensiones más utilizadas fueron 3.500 mm, $2.500 \mathrm{~mm}$ y $1.000 \mathrm{~mm}$ de largo por $851 \mathrm{~mm}$ de ancho. ganado ovino ${ }^{48}$. El mayor de los costos de esta ocupación económica fue la extinción de la población aborigen. En palabras de Mateo Martinic, «La gran responsable directa -por delito de acción- lo fue la colonización ganadera, como acción económica impersonal y anónima que en su avasallador desarrollo eliminó los obstáculos que se le oponían, pues su avance representaba una demostración manifiesta de progreso y civilización, no importando que aquel se amasara con sangre y dolor inocente y ésta resultara escarnecida» 49

Las estancias ganaderas son asentamientos rurales, formados por cascos, secciones, puestos, caminos, pequeños puertos, destinados a la crianza de ovejas para la producción de lana, carne y derivados. Constituyen polos arquitectónicos, múltiples, discretos y dispersos, de producción, referencia y orientación, que constituyeron lugares específicos del territorio. Sus elementos más significativos son los cascos de estancia, los más grandes de los cuales llegaron a albergar durante la época de esquila a un centenar de trabajadores. Estos cascos dieron origen a unas formas básicas de urbanidad, al modo de pequeños poblados compuestos por viviendas de distintas categorías, entre la que sobresale la casa de administración, desde la cual se ejercía el dominio visual, y las instalaciones productivas, entre las que se destaca el galpón de esquila, donde se concentra el foco productivo. Las prácticas constructivas crearon unas arquitecturas edificadas con estructuras de madera revestidas con planchas metálicas onduladas de hierro galvanizado ${ }^{50}$, conformando formas fuseladas destinadas a cumplir funciones laborales y residenciales. Sus dimensiones resultaron definidas en sus estructuras por el pie inglés, en sus revestimientos por las distintas dimensiones de las planchas metálicas ${ }^{51}$ y en sus funciones por el tamaño y los movimientos de las ovejas en el proceso de esquila

Con el correr del siglo xx, sin embargo, la expansión sostenida de la ganadería ovina fue contrayéndose en razón de aspectos tales como el clima riguroso en extremo, las distancias significativas entre las estancias y Porvenir, único centro poblado en la Isla hasta 1958, los restringidos medios de transporte y comunicación, la condición mono productora de los establecimientos, el empobrecimiento y deterioro de los suelos, la reducción de las superficies en explotación, el manejo técnico conservador de los predios ovejeros, entre otros. Muchas de las grandes estancias fueron abandonadas y no consiguieron dar 
Vista de casa en estancia Gente Grande (Wehrhahn y Cía.) (fuente: Piwonka, 2003)
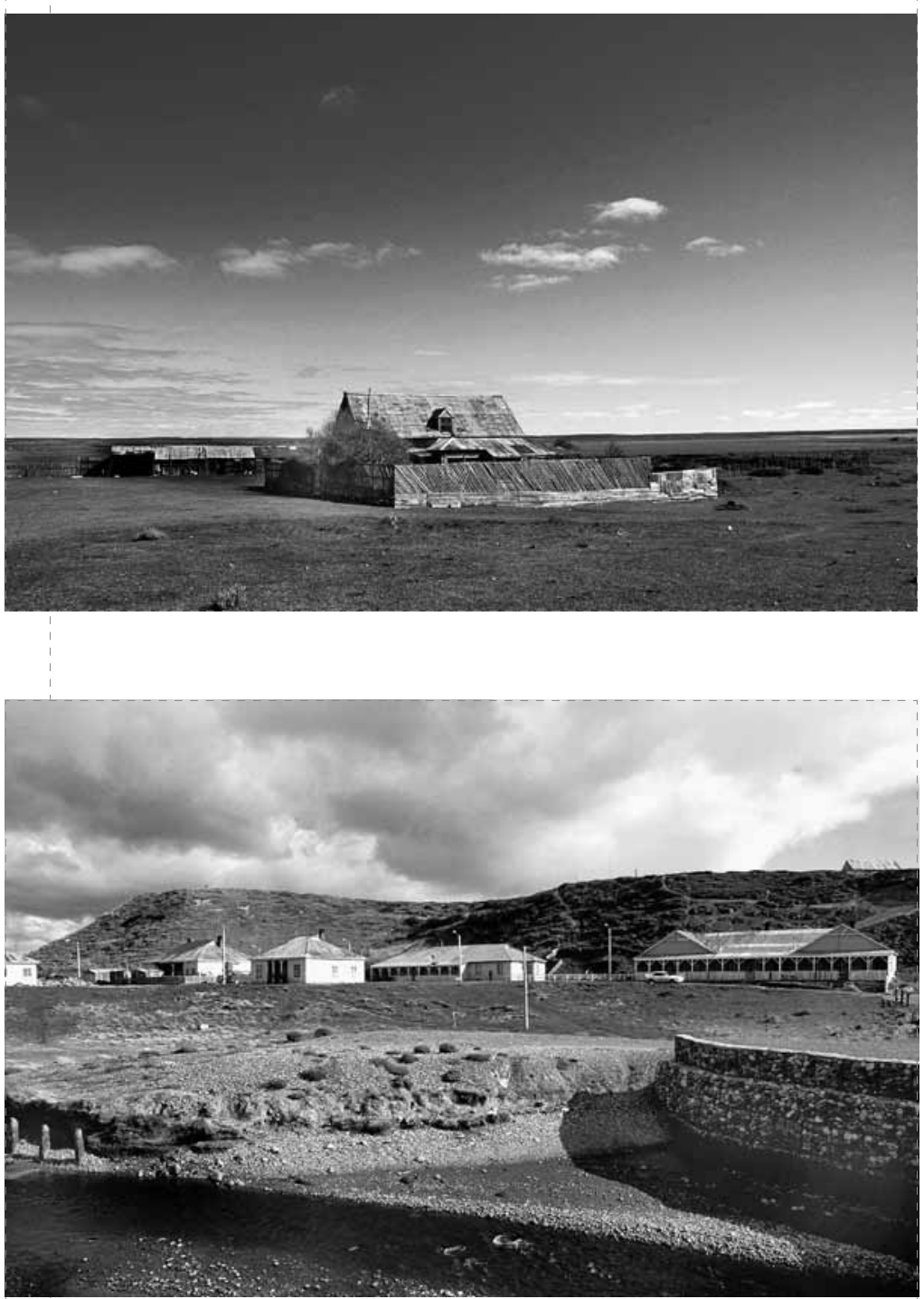

Vista de casco en estancia Cameron (Setf) (fuente: Piwonka, 2003).
Vista de galpón de esquila en estancia Springhill (The Tierra del Fuego Sheep Farming Co.) (fuente: Piwonka, 2003)
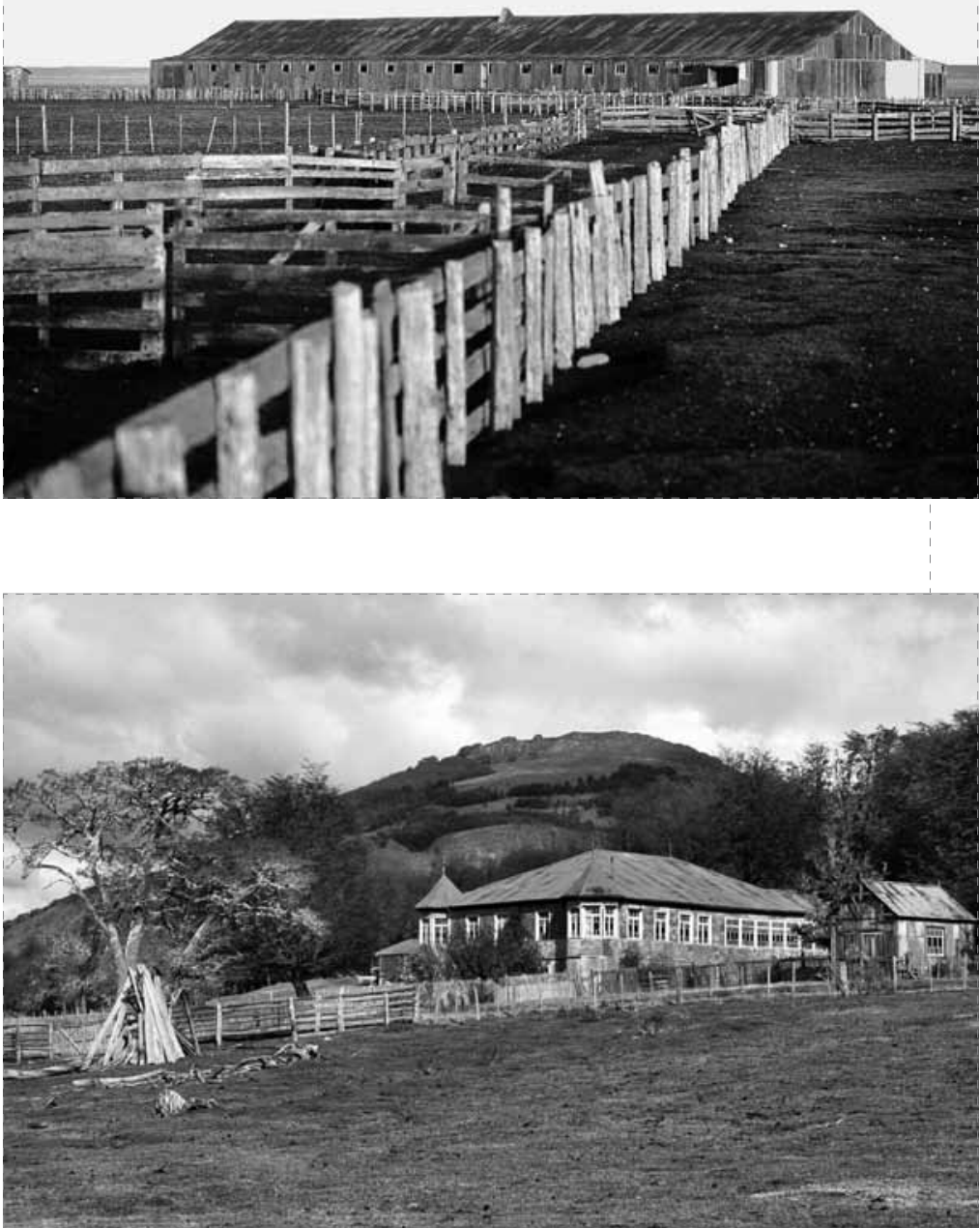

Vista de casa en estancia Vicuña (Sociedad Industrial y Ganadera de Magallanes) (fuente: Piwonka, 2003) pie a núcleos estables y complementarios de población ${ }^{52}$. Los principales cascos de estancias son: Gente Grande (1885), Springhill (1890), Caleta Josefina (1893), Bahía Felipe (1896), Cameron (1904), Vicuña (1915), Russfin (1920), China Creek (1924).

\section{La estancia Caleta Josefina ${ }^{53}$}

La empresa ganadera más importante que operó en la Isla fue la Sociedad Explotadora

52 Ver artículo de Mateo Martinic. En: Las formas de ocupación del territorio en Tierra del Fuego, 2005.

53 En este capítulo colaboró la arquitecta María José Cartagena. de Tierra del Fuego. La primera estancia formada por la Sociedad fue Caleta Josefina (1893), situada al poniente de la bahía Inútil y a 102 kilómetros de Porvenir. Su casco fue organizado en torno al proceso de producción lanar, en tres zonas bien caracterizadas. La primera, constituida por el galpón de esquila, sus corrales, rampas y baño para el ganado, fue ubicada en las vecindades del camino, de manera de conseguir una rápida conexión para la llegada y salida de los productos; la segunda, constituida por la casa de administración, fue ubicada en el otro extremo del casco, en un área aislada situada aguas arriba del conjunto; la tercera, constituida por el comedor-cocina, dependencias y viviendas secundarias, fue ubicada cerca del sector productivo. Otras instalaciones, complementarias de las mencionadas, fueron las perreras, talleres, huerta e invernadero, bodegas y establo, estanques de agua.

Actualmente quedan en pie 15 de ellas, de las cuales siete se encuentran en mediano estado de conservación y ocho en ruinas. Los elementos de su arquitectura son reconocibles en todas las estancias que formó la Sociedad: ventanas de guillotina, cubiertas a cuatro 


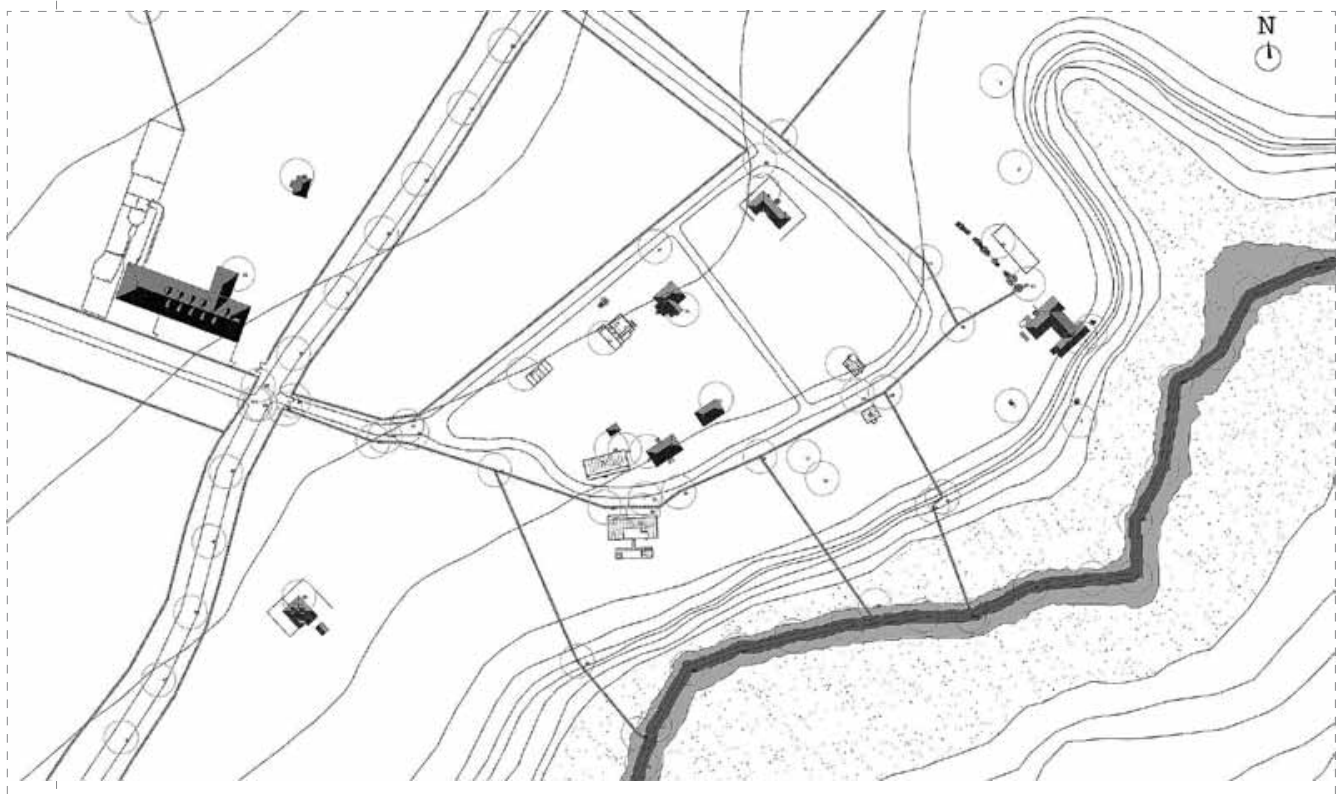

Planta del casco en estancia Caleta Josefina (fuente: Cartagena, 2005)

aguas, elementos de madera a 45 grados en el apoyo de pilares con vigas para dar rigidez a los nudos, corredores exteriores abiertos, en forma de veranda. Las construcciones originales llegaron a ser 36 unidades.

El galpón de esquila de Caleta Josefina es un gran cobertizo con dimensiones en planta de 76 metros por 24 metros y una altura máxima de 9,10 metros destinado a albergar a hombres y animales en un espacio interior seco y protegido del rudo clima austral para llevar a cabo la faena completa de la esquila, con un promedio de 5.000 ovejas diarias, así como la selección y el empacado de la lana. La forma del galpón se basa en una cubierta a cuatro aguas, de superficie continua con los paramentos laterales, todo revestido con planchas metálicas, y el agregado de elementos modulares, como ventanas y lucernarios, consiguiendo un fuselaje arquitectónico por el que fluyen de mejor manera los vientos dominantes, factor condicionante de la arquitectura en Tierra del
Fuego. Las cerchas de cubierta salvan una luz de 24 metros y fueron articuladas con los paramentos laterales mediante elementos en diagonal para lograr su buen arrostramiento. El conjunto fue estructurado con madera nativa de lenga (Nothofagus Pumilio), que se soporta sobre una plataforma de tablones de madera con vigas del mismo material, apoyadas a una altura de 1,20 metros de promedio respecto del terreno natural, sobre poyos de hormigón armado, en los cuales se habría utilizado por primera vez en Chile el cemento Portland. El galpón está ubicado en un lugar seco y accesible, aislado de los otros edificios para contar con una buena superficie de espacio libre exterior y facilitar el manejo de las ovejas en las distintas etapas de las faenas, mediante corrales, rampas y cercos.

La arquitectura de la madera cobijó la vida en las viviendas de las estancias de Tierra del Fuego con tipos edificatorios y elementos arquitectónicos construidos con procedimientos sencillos y eficaces adaptados a los programas de residencia. Las viviendas se diferenciaron de acuerdo con los distintos roles que cumplían sus usuarios: administrador, empleados, trabajadores permanentes y trabajadores temporales.

Las viviendas de empleados estaban destinadas a personal con cargos secundarios -segundo administrador, contador, capataces ${ }^{54}$ y cadetes- en algunos casos acompañados de su grupo familiar. Las viviendas para obreros permanentes ${ }^{55}$ eran ocupadas por peones destinados al cuidado constante del ganado ovino durante el año, además de faenas de manutención en el galpón de esquila. La distribución interior presenta una zona de estar con estufa a leña, en posición central respecto de la planta, hacia la cual convergen os dormitorios. Las viviendas para obreros temporales estaban destinadas al alojamiento de comparsas ${ }^{56}$, las que hasta hoy en día se trasladan de casco en casco en la época de esquila de las ovejas. Disponen de un estar central con estufa y un pasillo central al que abren las habitaciones. En ambos casos, las viviendas no tenían baño, cocina o comedor, ya que sus ocupantes usaban para estos efectos las instalaciones comunes del casco.

La casa de administración ${ }^{57}$ de Caleta Josefina se encuentra ubicada en un lugar estratégico de dominio para controlar el funcionamiento de las actividades del casco y proyectar al mismo tiempo una imagen de autoridad y dominio ${ }^{58}$. Tiene un total de 420 metros cuadrados distribuidos en 23 recintos. El área pública está formada por un salón de estar y el comedor, ambos con chimenea, y la galería. El área de habitaciones posee una serie de recintos de superficie equivalente, algunos de ellos con chimenea, dispuestos en doble crujía, con orientaciones nororiente y surponiente. El área de servicios cuenta con recintos menores organizados en torno a la cocina y un acceso independiente. El área de trabajo y oficinas se alinea a lo largo de un volumen complementario, con un pasillo lateral y acceso que lo comunica con el sector productivo de la estancia. La vivienda posee un total de siete chimeneas, tres de las cuales son dobles, las que temperan los espacios

54 «El capataz tiene a su cuidado la vigilancia inmediata de sus ovejeros; las translaciones oportunas del ganado en los campos; las faenas de marca, baños, esquila, etc., puede haber más de un capataz teniendo a su cargo cada uno determinadas faenas. [£15-20 al mes]». José Miguel Yrarrázaval. El ganado lanar en Magallanes, p. 82.

55 «Existen desde la primera clase hasta aprendices. El número depende de la cantidad de ganado a atender en cada estancia. Se necesita un ovejero por cada 4.000 a 5.000 ovejas. La mayor parte de los ovejeros son de origen inglés, especialmente escoceses [£5-8 al mes]». José Miguel Yrarrázaval. El ganado lanar en Magallanes, p. 82.

56 Una comparsa es un grupo de peones de esquila que la empresa ganadera contrata para realizara la faena de la esquila.

57 «Toda estancia está a cargo de un administrador, cuya calidad y honorarios varían según la importancia de la misma. La mayoría de los administradores de las estancias grandes en Magallanes son de origen inglés. Las sociedades y particulares, propietarios de una estancia abonan al administrador todos los gastos de casa y servidumbre, más honorarios. [£700 al año]». José Miguel Yrarrázaval. El ganado lanar en Magallanes, p. 81.

58 «El Administrador no se roza con ninguno de sus subordinados y sólo hace vida social, dentro de su hogar, con los escasos visitantes extraños a su dirección. Se visita constantemente con sus congéneres de las otras estancias o sostiene con ellos prolongadas conversaciones telefónicas». Arturo Fuentes Rabé. Tierra del Fuego, capítulo VI. 
Detalle del galpón de esquila en estancia Caleta Josefina (fuente: Cartagena, 2005).

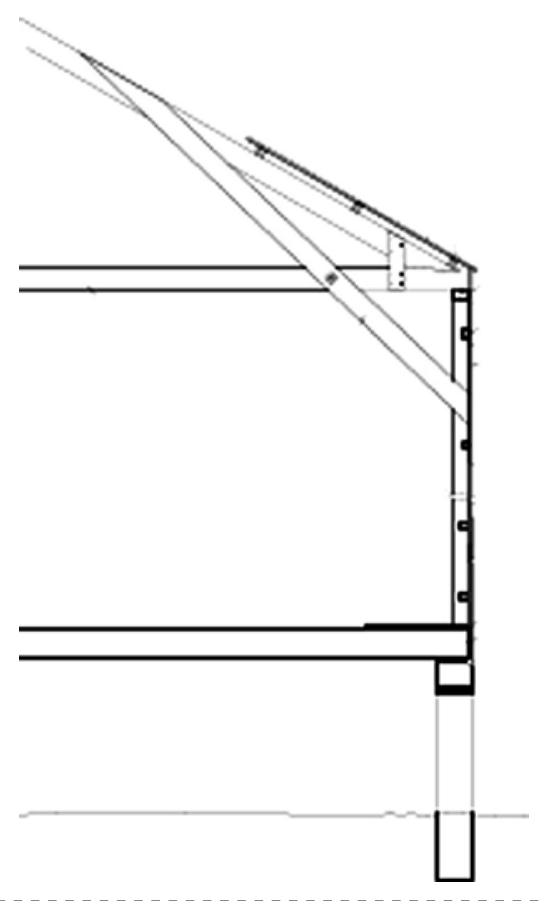

Vista del galpón de esquila en estancia Caleta Josefina

(fuente: Garcés, 2008).

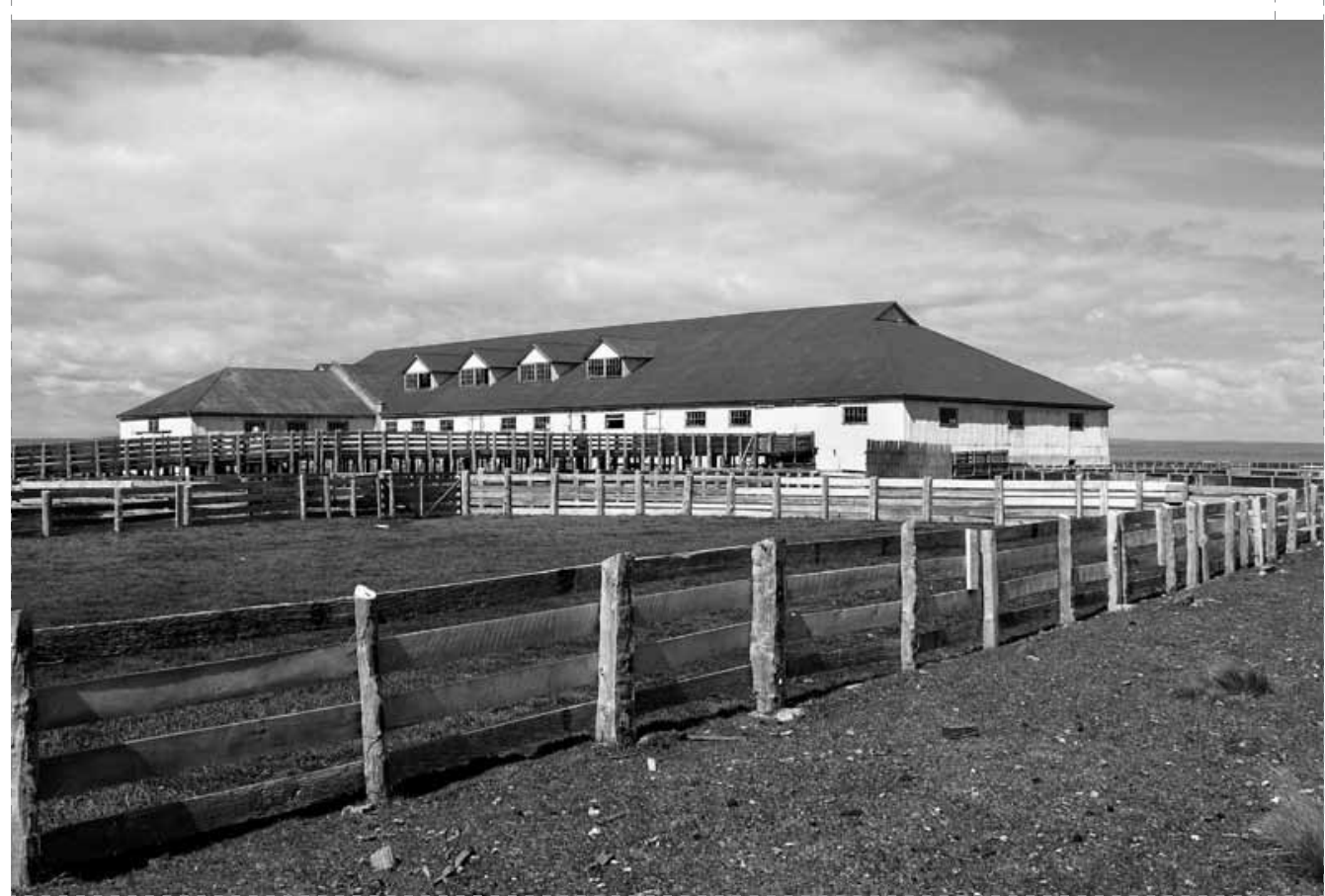

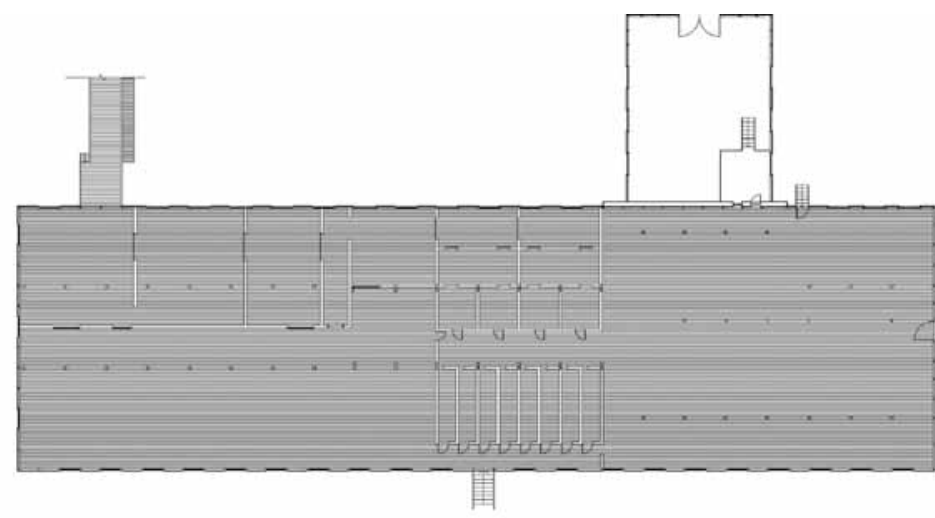
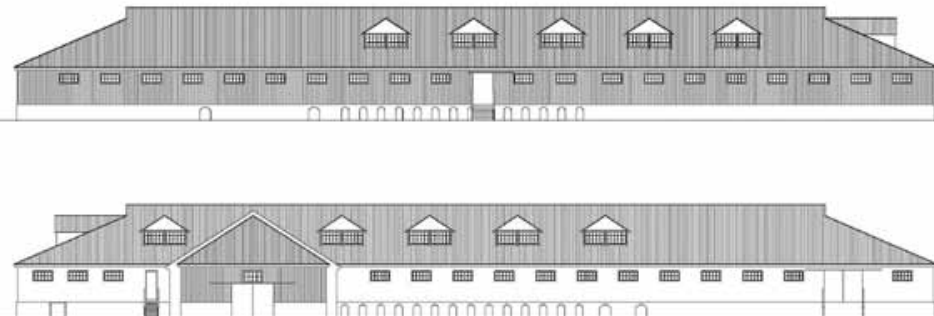

Planta y fachadas del galpón de esquila en estancia Caleta Josefina (fuente: Cartagena, 2005).

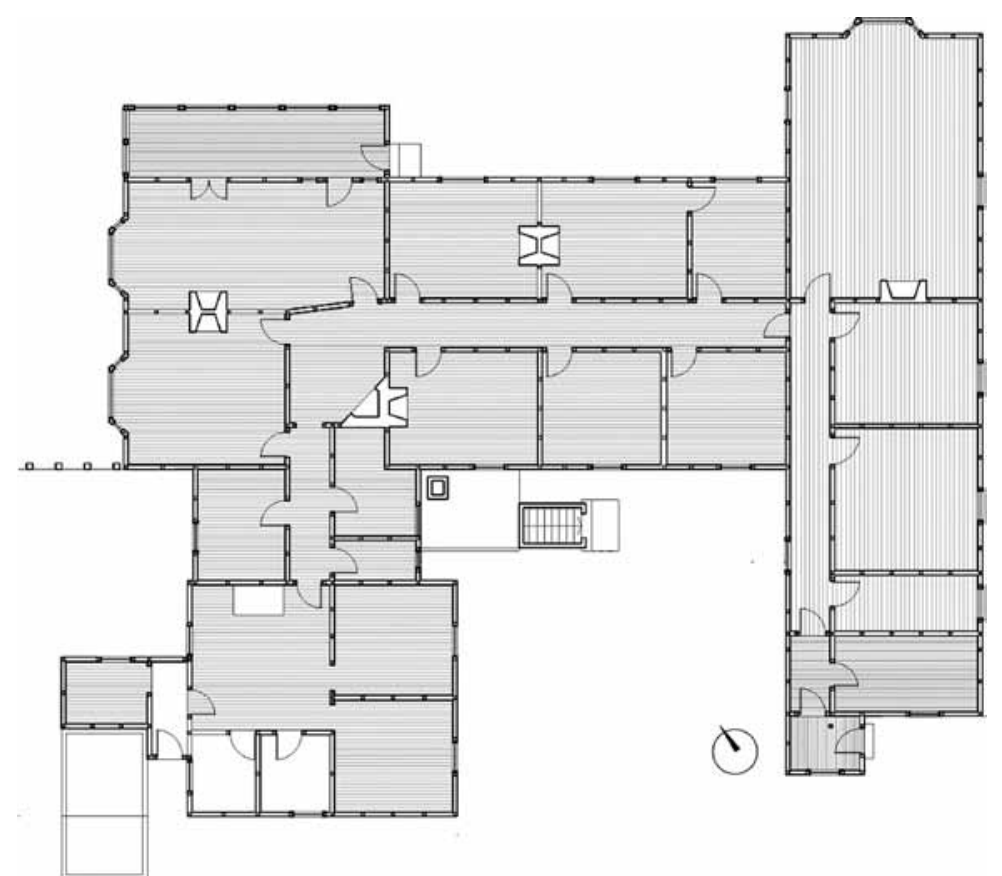

Planta de la casa de administración en estancia Caleta Josefina

(fuente: Cartagena, 2005). 

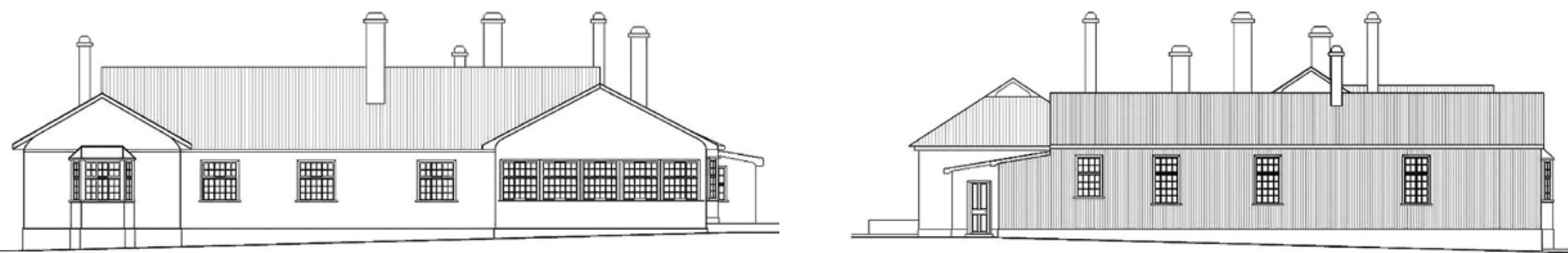

Fachadas de la casa de administración en estancia Caleta Josefina (fuente: Cartagena, 2005).

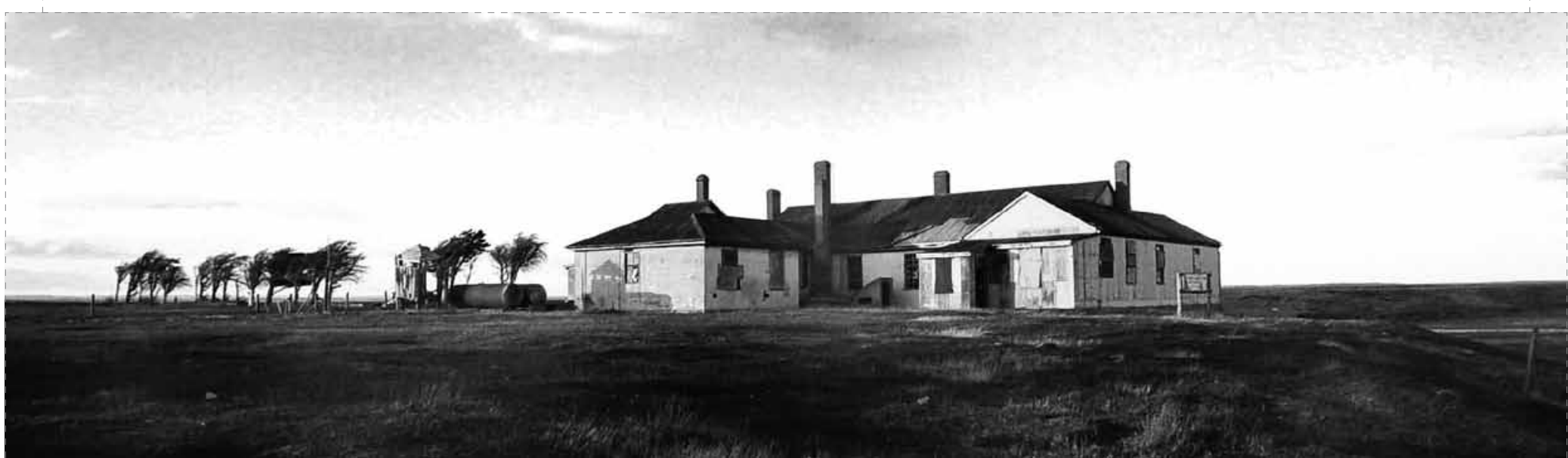

Vista de la casa de administración en estancia Caleta Josefina (fuente: Seisdedos, 2003).

domésticos, organizan sus programas, cualifican los recintos al amparo del calor de hogar e imponen la imagen y el rango de la empresa con la exhibición de las numerosas salidas de humo en cubierta. La galería es un espacio intermedio de reiterada presencia en la arquitectura de Tierra del Fuego, como expresión de unas formas de vida en una latitud austral, que capta la luz, el calor y las vistas del paisaje desde un espacio situado entre la intemperie del territorio y la temperie de los recintos domésticos, entre la vastedad del espacio geográfico y lo acotado de los recintos de residencia.

La casa de administración, de propiedad de Ejército de Chile, está abandonada, aunque no se descarta la idea de que sea traspasada a los privados, para su recuperación patrimonial.
Tierгa del Fuego, paisajes culturales extremos

La Tierra del Fuego se identifica por sus paisajes naturales extraordinarios que poseen magnitud, escala, complejidad, grado de dificultad, etc., con características de prístino, remoto, distante, intenso, excesivo, etc. Sobre ellos se asentó, desde hace unos ciento diez siglos, la rica cultura aborigen de los sélknam, cuya expresión territorial fueron los háruwen. A su vez, en el área se llevaron a cabo una serie de exploraciones, registros y narraciones realizadas por exploradores europeos, a partir del descubrimiento del Estrecho de Magallanes en 1520, que encuentran su forma más acabada en la valiosa cartografía fueguina. Por último, y desde fines del siglo xIX, se desarrolló en la Isla un conjunto de asentamientos humanos que surgieron a raíz de una colonización económica basada en la explotación de sus recursos naturales -oro, pradera, petróleo, paisajes- cuya expresión territorial son los company lands agrarios y minero.

La idea de paisajes culturales extremos en Tierra del Fuego constituye un conjunto integrado, superpuesto y acumulado de capas antrópicas ${ }^{59}$ de ocupación, sobre unos paisajes naturales extraordinarios, compuesto por historias, formas, estructuras y funciones, sujetas a desarrollos y cambios ${ }^{60}$, en la que se verifican las complejas interdependencias entre ambiente natural extremo, prácticas sociales aborígenes, exploraciones, registros y emprendimientos económicos. Estos hechos representan obras conjuntas del hombre y

El principio antrópico sugiere que vivimos en un universo que parece haber sido meticulosamente adaptado para permitir la existencia de la vida tal y como la conocemos.

60 Carl Sauer. «Objetivo de la geografía». En: La morfología del paisaje, 1925. 
la naturaleza que ilustran la relación intensa, poderosa y vital que la sociedad aborigen primero y unas empresas económicas de colonización más tarde, establecieron en el extremo territorio fueguino, modificando su ambiente con finalidades productivas y configurando con el tiempo una identidad fueguina que subyace en esa construcción cultural del paisaje.

La interpretación en términos de layers de compleja lectura, asociada con la noción de palimpsesto, caracteriza un territorio cultura extremo que surge de la superposición de múltiples sedimentos culturales, pasados y presentes, resultados de la construcción de territorios dinámicos y superpuestos, en los cuales se conservan los débiles registros de la ocupación aborigen, sobre la que se impuso la explotación aurífera, la ocupación pastoril, la explotación de hidrocarburos, la industria forestal y el turismo.

Del háruwen al company land, estas capas han sido articuladas mediante un conjunto de espacios residenciales y productivos, materialmente frágiles ${ }^{61}$ pero densos en sus significados, posibilidades y proyecciones económicas y culturales, que se constituyen en referencias persistentes de la identidad regional y de la sociedad magallánica. Los centros poblados, representados por el puerto de Porvenir, el company land minero, representado por el campamento de Cerro Sombrero, y los company lands agrarios, representados por las estancias ganaderas, se constituyen en referencias persistentes de la identidad regional y de la sociedad magallánica. En conjunto con la ocupación aborigen, contribuyen con la caracterización de un finis terrae incógnito, territorio de frontera en el cual se pone en evidencia esa transformación de su naturaleza extrema en cultura, sobre un ámbito geográfico dominado por la noción de vastedad en su latitud austral

Estos antecedentes nos permiten afirmar que si el paisaje extremo es actualmente uno de sus recursos naturales, su interpretación cultural agrega valor a Tierra del Fuego. De esta hipótesis surgen numerosos retos para la gestión del territorio, entre ellos su ordenación funcional, la dotación de infraestructura y su activación para el turismo de intereses especiales.
De manera que los paisajes naturales son el molde y la horma donde se han formado los paisajes culturales extremos en Tierra de Fuego, a la manera de capas superpuestas como en un palimpsesto, establecidos en un conjunto de intensos paisajes de excepcional belleza y riguroso clima, que fueron registrados por navegantes y exploradores europeos a lo largo de cuatrocientos años de historia, y que trasciende al territorio físico propiamente tal para instalarse en la fantasía cultural de occidente como imaginario ${ }^{62}$ de un confín remoto más allá del cual no es posible avanzar.

\section{Bibliografía}

- AAVV. 12 Miradas sobre sélknam, yaganes y kawesqar. Editado por Carolina Odone y Meter Manson. Santiago: Taller Experimental Cuerpos Pintados Ltda, 2003.

- Anales del Instituto de la Patagonia Ciencias Humanas. Volumen 21. Punta Arenas.

- Dante Baeriswyl. Arquitectura en Punta Arenas. Casas de madera. Punta Arenas: Editorial Hielos Antárticos Ltda, 2003.

- Juan Benavides et al. Las estancias magallánicas. Santiago: Editorial Universitaria 1999.

- Armando Braun Menéndez. Pequeña historia fueguina. Buenos Aires, Santiago de Chile: Editorial Francisco de Aguirre, 1971

- A. Corboz. «El territorio como palimpsesto». En: Martín Ramos. Lo urbano en 20 autores contemporáneos. Barcelona: Ediciones UPC 2004.

- $\quad$ Anne Chapman. Los sélknam. La vida de los onas. Buenos Aires: Emecé Editores, 1986.

- Bruce Chatwin, Paul Theroux. Retorno a la patagonia. Madrid: Grupo Anaya SA, 1997.

- Charles Darwin. Darwin en Chile. Santiago: Editorial Universitaria, 1996.

- Alberto de Agostini. Esfinges de hielo. Torino: Industria Libraria Tipográfica Editrice, 1959.

- Francisco A. Encina. Resumen de la historia de Chile. Redacción, iconografía y notas de Leopoldo Castedo. $1^{\text {ra }}$ ed. Santiago: Zig-Zag, 1984.

- $\quad M^{a}$ del Milagro Escribano et al. El paisaje. Madrid: MOPT, 1991.

- Arturo Fuentes Rabé. Tierra del Fuego. Tomos I y II. Santiago: Editorial Andujar, 1999.

- Eugenio Garcés Feliú et al. Las ciudades del cobre. Santiago: Ediciones UC, 2007.

- Eugenio Garcés Feliú. Las ciudades del salitre. Santiago: Orígenes, 1999

- Eugenio Garcés Feliú et al. Las formas de ocupación del territorio en Tierra del Fuego.
Santiago: Facultad de Arquitectura, Diseño y Estudios Urbanos, Universidad Católica, 2005.

- Eugenio Garcés Feliú, Franz Kroeger. Taller de Investigación $2^{\text {do }}$ Semestre 2008: «Arquitectura y representación en territorios extremos. Mapping de rutas culturales en Tierra del Fuego". Santiago: Escuela de Arquitectura, Universidad Católica, 2008

- Clara García Moro. «Reconstrucción del proceso de extinción de los sélknam a través de los libros misionales». En: Anales del Instituto de la Patagonia Cs. Hs. 1987; 21.

- Vittorio Gregotti. El territorio de la arquitectura. Barcelona: Editorial Gustavo Gili, 1972.

- Martín Gusinde. Expedición a Tierra del Fuego. Santiago: Editorial Universitaria, 1980.

- Alfredo Jocelyn-Holt. Historia general de Chile. Santiago: Editorial Sudamericana, 2008.

- Carlos Keller. Dios en Tierra del Fuego. Santiago: Editorial Zig-Zag, 1947.

- Mariano Latorre. Chile, país de rincones. Santiago: Editorial Universitaria, 2000.

- Liliana Lolich. Patagonia, arquitectura de estancias. Buenos Aires: CEDODAL, 2003.

- Mateo Martinic. Cartografía magallánica 15231945. Punta Arenas: Ediciones de la Universidad de Magallanes, 1999.

- Mateo Martinic. La Tierra de los Fuegos. Porvenir: Municipalidad de Porvenir, 1980

- José Ricardo Morales. Arquitectónica. Santiago: Universidad del Biobío, 1984.

- César Naselli. El paisaje territorial. En: MW 2007 9.

- Leonel Pérez. La mirada y la memoria. Tesis Doctoral UPC, 2007

- Julius Popper. Atlanta. Buenos Aires: Eudeba, 2003.

- Alfredo Prieto. El arco y la flecha de los sélknam. Santiago: Museo Precolombino, Biblioteca PDF, Patagonia, 2008

- Revista CA 2001; 106.

- Revista MW 2007; 9.

- Revista Quaderns Extra №s 1 y 2 s/f.

- Joaquín Sabaté. «Paisajes culturales. El patrimonio como recurso básico para un nuevo modelo de desarrollo (río Llobregat)». Revista Urban 2004

- Benjamín Subercaseaux. Chile o una loca geografía. Santiago: Editorial Universitaria, 2001.

- Carl Sauer. «La morfología del paisaje». Traducción de Guillermo Castro H. University of California Publications in Geography 1925; 2(2): pp. 19-53.

- Manuel Solá-Morales. «Reconocimiento comarcal y ordenación del territorio». Revista Quaderns Extra, №s 1 y 2 .

- José Miguel Yrarrázaval. El ganado lanar en Magallanes.

61 En el caso de los háruwen solo restan sus registros, debidos a Martín Gusinde, los que a su vez son interpretaciones de datos transmitidos por una cultura oral. Por su parte, la arquitectura en madera, dependiendo de su manutención, tiene una duración más limitada que la de piedra o ladrillo.

62 Chatwin y Theroux, en su libro Retorno a la Patagonia (1997), examinan las múltiples menciones a la Patagonia y Tierra del Fuego en diversos escritores, entre ellos Poe, Melville, Coleridge, Donne, Hudson y otros. 